International Geosphere=-Biosphere Programme

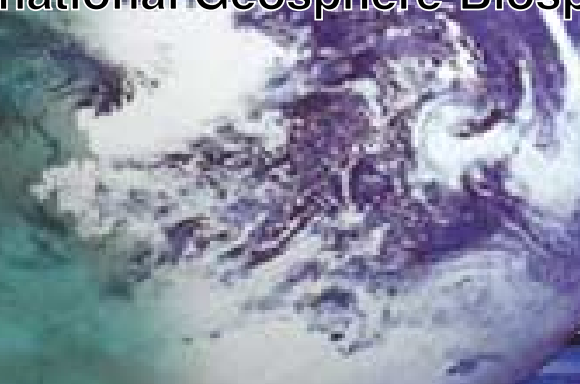

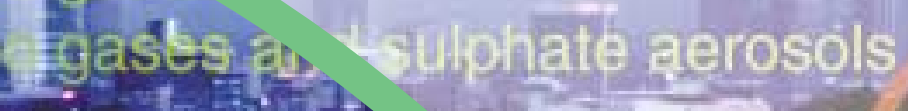

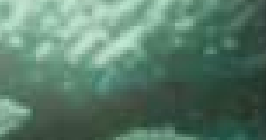

Tyon 3

$-1+x^{2}-2$

$$
\text { 4. - - }=
$$

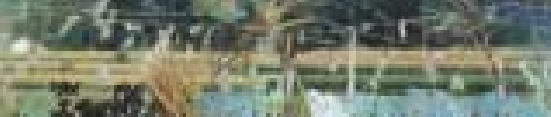

ar)
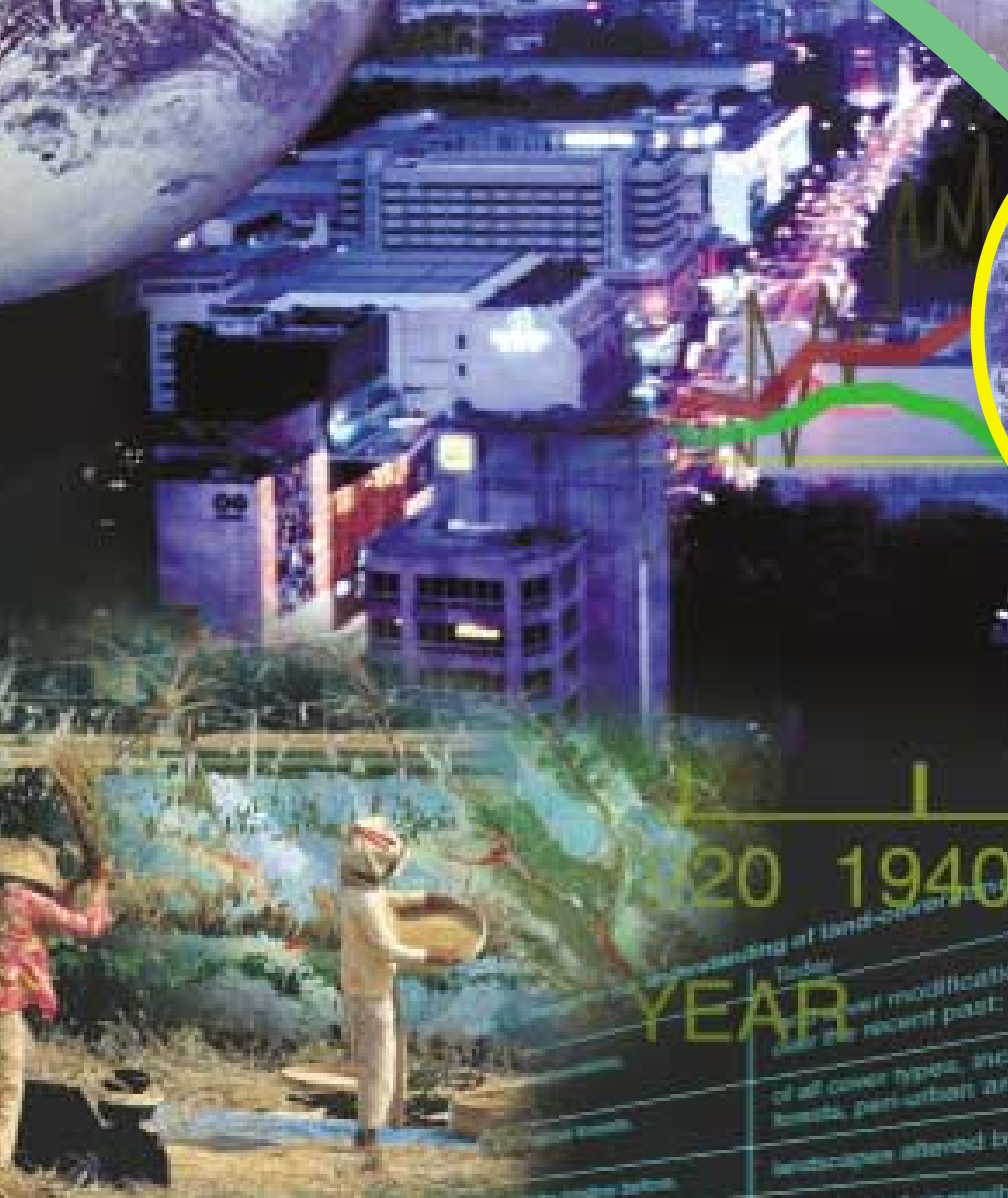

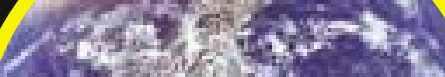

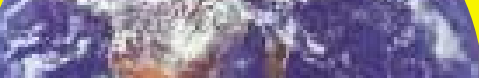

sest
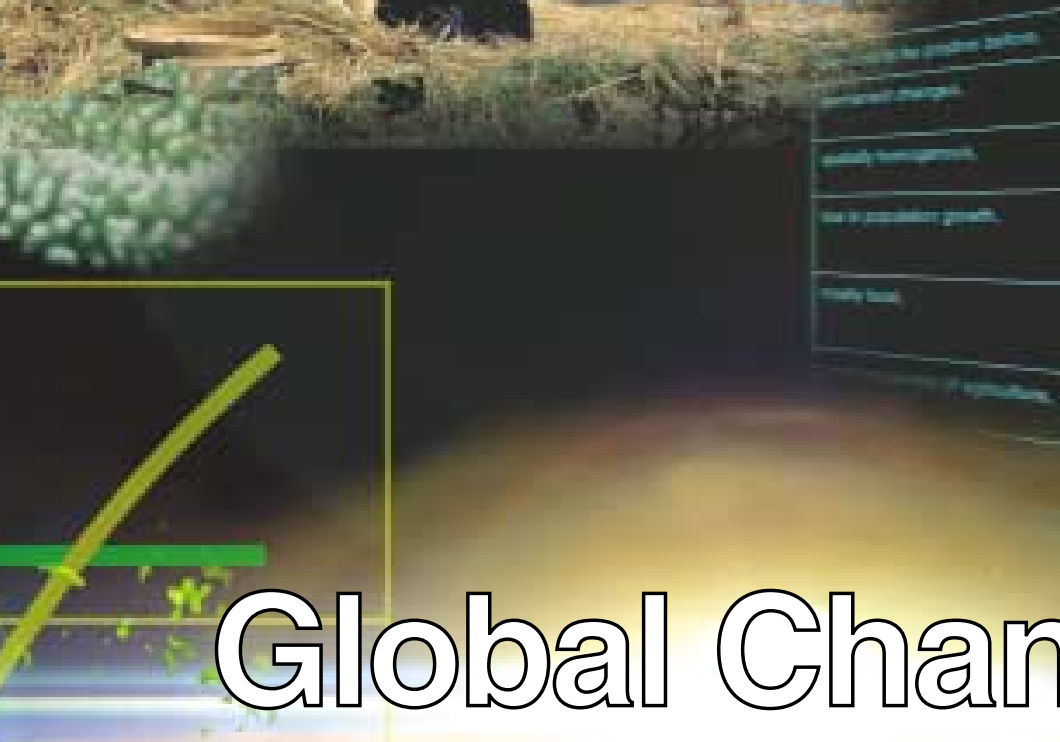

$201940+196019$

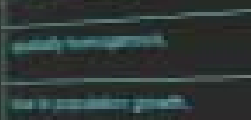

EA

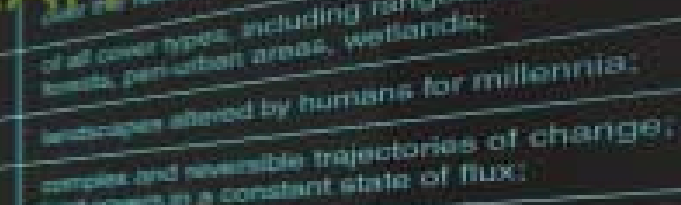

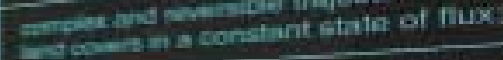

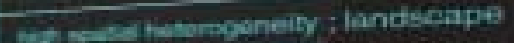

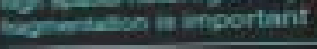

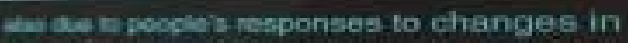

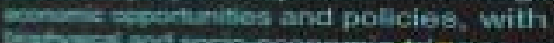

-

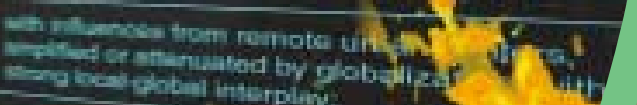

$5 x^{2}=1$ का

जigy

sine

Langts

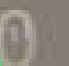




\section{Foreword}

The world faces significant environmental problems: shortages of clean and accessible freshwater, degradation of terrestrial and aquatic ecosystems, increases in soil erosion, loss of biodiversity, changes in the chemistry of the atmosphere, declines in fisheries, and the possibility of significant changes in climate. These changes are occurring over and above the stresses imposed by the natural variability of a dynamic planet and are intersecting with the effects of past and existing patterns of conflict, poverty, disease, and malnutrition.

The changes taking place are, in fact, changes in the human-nature relationship. They are recent, they are profound, and many are accelerating. They are cascading through the Earth's environment in ways that are difficult to understand and often impossible to predict. Surprises abound. At least, these human-driven changes to the global environment will require societies to develop a multitude of creative response and adaptation strategies. Some are adapting already; most are not. At worst, they may drive the Earth itself into a different state that may be much less hospitable to humans and other forms of life.

As global environmental change assumes a more central place in human affairs, science is being thrust into the unfamiliar and uncomfortable role of a major player in a heated and potentially divisive international debate about the nature and severity of global change and its implications for ways of life. Much is at stake and the game is being played hard. Despite the risks, science must accept the responsibility of developing and communicating the essential knowledge base that societies can use to debate, consider and ultimately decide on how to respond to global change.

The past decade of global change research, summarised in this booklet, has unveiled more and more about the complex and interrelated nature of the Earth System, and about the ways in which human activities are impacting the System. Much exciting science has been carried out and much has been achieved. Above all, we know that the Earth System has moved well outside the range of natural variability exhibited over the last half million years at least. The nature of changes now occurring simultaneously in the global environment, their magnitudes and rates, are unprecedented in human history, and probably in the history of the planet. The Earth is now operating in a no-analogue state.

On the other hand, we do not yet know where critical thresholds may lie. Nor can we say if, when and how the increasing human enterprise will propel the Earth System towards and across the boundaries to different states of the global environment. We also do not know the features or operating modes of the Earth System that are particularly robust, which when combined with human ingenuity with creative technological, institutional and ethical development - might lead to a safe transition to sustainability. Global change science has contributed much to an understanding of the Earth System but there is much to be done.

The challenge of ensuring a sustainable future is daunting and it is immediate. The challenge CAN be met, but only with a new and even more vigorous approach to an integrated Earth System science. This summary represents a small but important step towards confronting the future, towards building an integrated Earth System science and towards meeting the great challenge of global sustainability.

$\begin{array}{llll}\text { Berrien Moore III } & \text { Arild Underdal } & \text { Peter Lemke } & \text { Michel Loreau } \\ \text { Chair, IGBP } & \text { Chair, IHDP } & \text { Chair, WCRP } & \text { Co-Chair, DIVERSITAS }\end{array}$


- Foreword

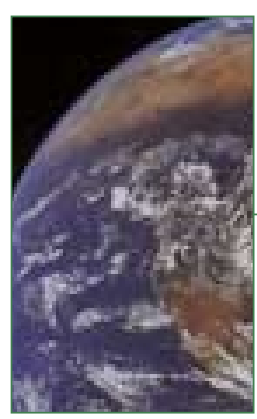

2 - Science Highlights

4 - An Integrated Earth System

The human-nature relationship

The Earth as a system

Global Change

7 - Planetary Machinery

Role of the biosphere

Temporal variability

Linkages and connectivities

Abrupt changes and critical thresholds

11 - The Anthropocene Era

The nature of global change

Drivers of change

An Earth System perspective

15 - Reverberations of Change

Long-term perspectives

Cascading impacts

Interacting processes and feedbacks

19 - Living with Global Change

Anticipating the consequences

Multiple, interacting effects

Risks for the Earth System

23 - Making Earth System Science

The dawn of a new era

Questions at the frontier

Coping with complexity and irregularity

The Earth System toolkit

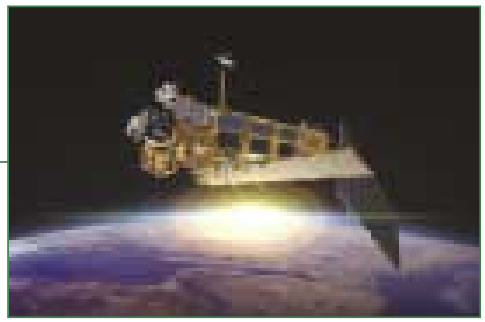

27 - Towards Global Sustainability?

Good management of the Earth System

Advancing sectoral wisdom

Global science for global sustainability

30 - Challenges of a changing Earth

31 - Appendix: About the Global Enviromental Change Programmes 
Somewhat more than a decade ago it was recognised that the Earthbehaves as a system in which the oceans, atmosphere and land, and the living and non-living parts therin, were all connected. While accepted by many, this working hypothesis seldom formed the basis for global change research. Little understanding existed of how the Earth worked as a system, how the parts were connected, or even about the importance of the various component parts of the system. Feedback mechanisms were not always clearly understood, nor were the dynamics controlling the system.

Over the intervening years much has been learned. In many respects former uncertainties about the nature and future course of global change have been reduced. In others, the realisation that uncertainty is an inherent part of the system has gained credence. Over the last 10 years the understanding of how humans are bringing about global change has undergone a quantum jump. Attempts to separate natural and anthropogenically induced variability in the Earth System have proved to be successful in many respects. The decade has been one of scientific challenge, achievement and excitement.

The scientific landscape is very different now from that of the late $1980 \mathrm{~s}$. In general, global change research has confirmed many of the hypotheses and much of the sketchy understanding of a decade ago, adding a wealth of quantitative detail and process-level understanding at all scales. Largely through a significant increase in the ability to unravel the past, the understanding of the natural dynamics of the Earth System has advanced greatly. It is now clear that global change is one of the paramount environmental issues facing humankind at the beginning of the new millennium.

The task of synthesising a decade of global change research has been daunting, but the rewards have been great. Detailed results and individual references cannot be presented here.These must be sought from the individual core project syntheses and the IGBP-wide synthesis, soon to be published by Springer Verlag in the IGBP book series. In this summary only generalised highlights are presented, the so-called big-picture findings. They are based on detailed, quantitative science that has been published by a multitude of scientists working worldwide over the past 10 years and longer.

\section{Major research findings:}

- The Earth is a system that life itself helps to control. Biological processes interact strongly with physical and chemical processes to create the planetary environment, but biology plays a much stronger role than previously thought in keeping Earth's environment within habitable limits.

- Global change is much more than climate change. It is real, it is happening now and it is accelerating. Human activities are significantly influencing the functioning of the Earth System in many ways; anthropogenic changes are clearly identifiable beyond natural variability and are equal to some of the great forces of nature in their extent and impact.
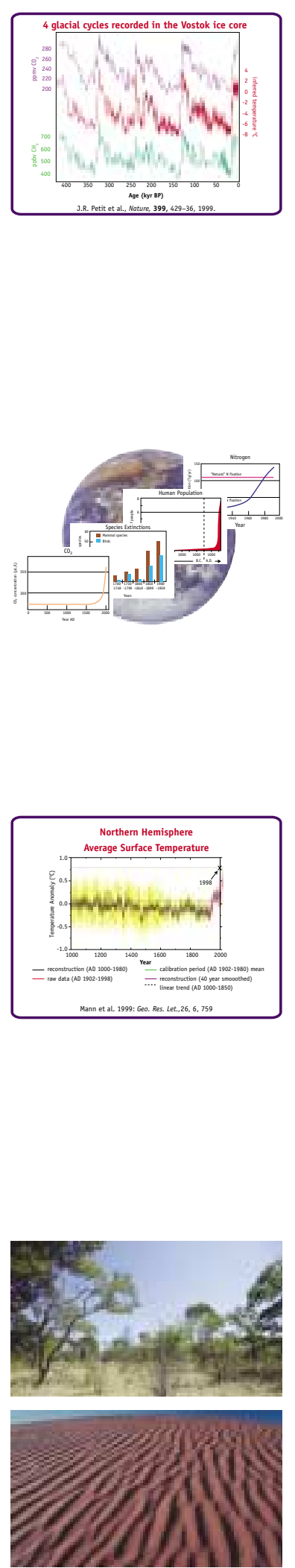

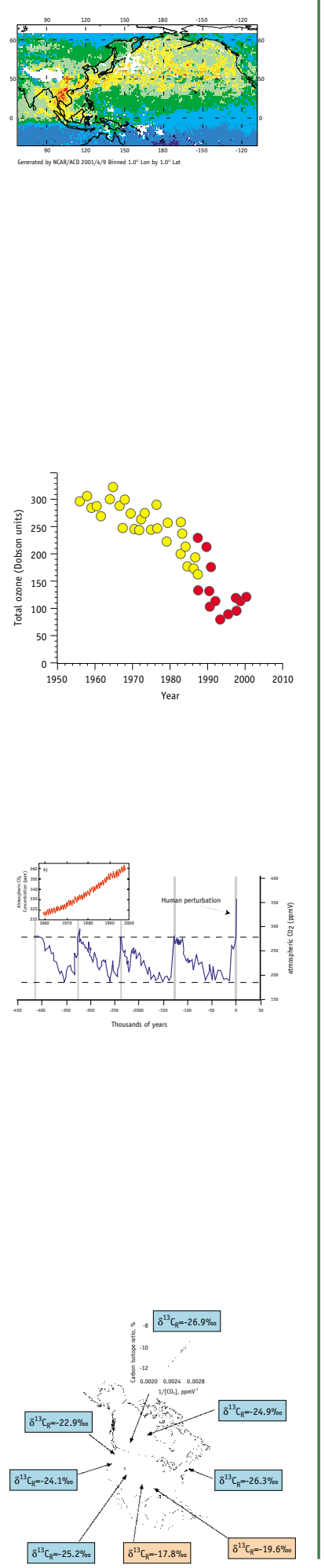

- The human enterprise drives multiple, interacting effects that cascade through the Earth System in complex ways. Global change cannot be understood in terms of a simple cause-effect paradigm. Cascading effects of human activities interact with each other and with local- and regional-scale changes in multidimensional ways.

- The Earth's dynamics are characterised by critical thresholds and abrupt changes. Human activities could inadvertently trigger changes with catastrophic consequences for the Earth System. Indeed, it appears that such a change was narrowly avoided in the case of depletion of the stratospheric ozone layer. The Earth System has operated in different quasi-stable states, with abrupt changes occurring between them over the last half million years. Human activities clearly have the potential to switch the Earth System to alternative modes of operation that may prove irreversible.

- The Earth is currently operating in a no-analogue state. In terms of key environmental parameters, the Earth System has recently moved well outside the range of the natural variability exhibited over at least the last half million years. The nature of changes now occurring simultaneously in the Earth System, their magnitudes and rates of change are unprecedented.

These scientific results lead directly to two important conclusions, one for the nature of the societal response required to address global environmental change and the other for the type of science needed to understand the Earth System.

- Ethics of global stewardship and strategies for Earth System management are urgently needed. The inadvertent anthropogenic transformation of the planetary environment is, in effect, already a form of management, or rather mismanagement. It is not sustainable. Therefore, the business-as-usual way of dealing with the Earth has to be replaced - as soon as possible - by deliberate strategies of good management.

- A novel system of global environmental science is emerging. The largely independent efforts of various international research programmes and numerous national projects create the basis for an Earth System science that is capable of tackling the cognitive tasks suggested by the research findings above. This new science will employ innovative integration methodologies, organize itself into a global system with transnational infrastructures, and embark on a continuing dialogue with stakeholders around the world. 


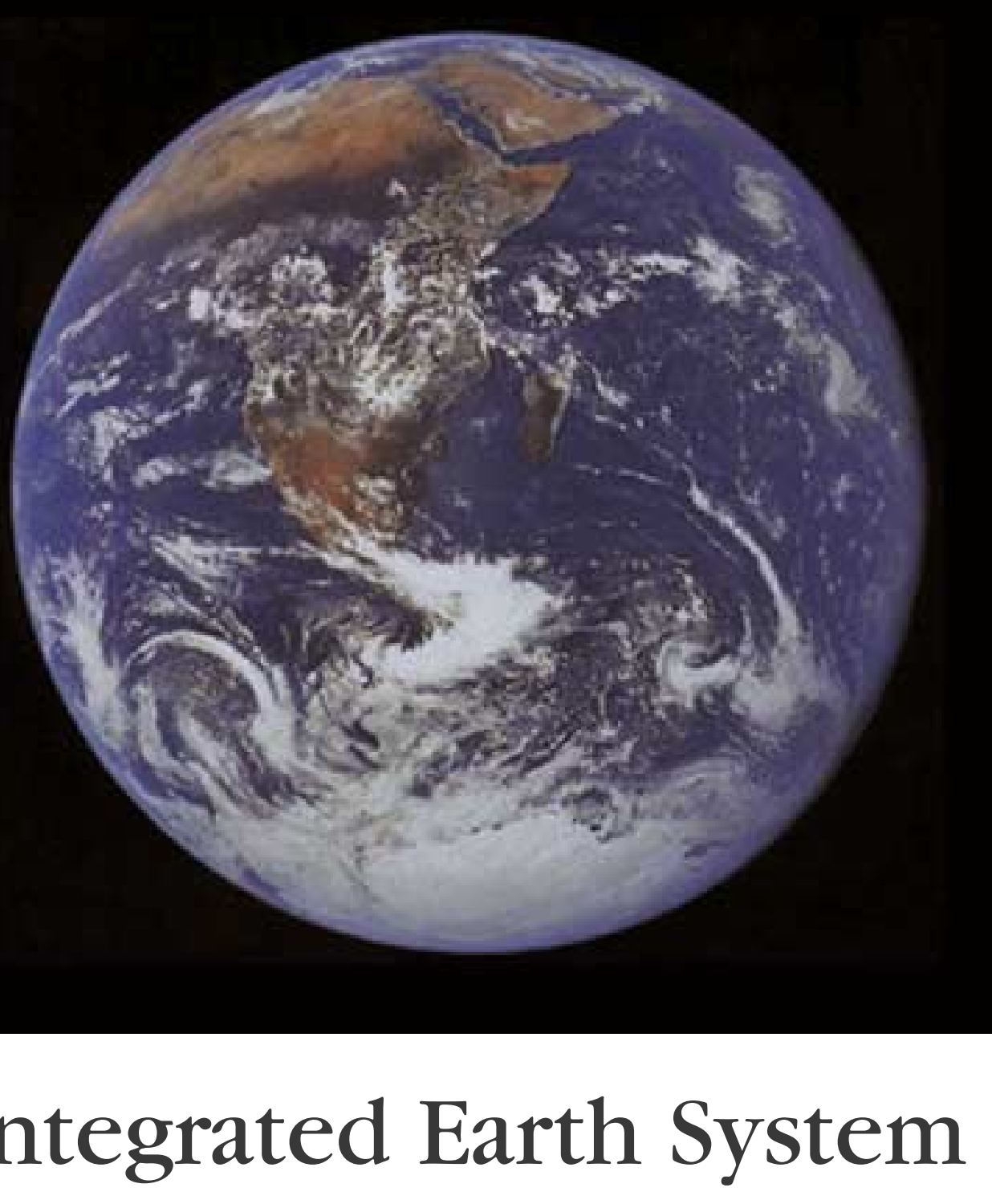

\section{An Integrated Earth System}

Over the last two decades a new imperative has come to dominate environmental concerns. With a rapidly increasing understanding of the nature of Earth's life support system, a growing awareness has emerged that human activities are exerting an ever accelerating influence on aspects of Earth System functioning upon which the welfare and the future of human societies depend.

\section{The human-nature relationship}

the INTERACTIONS bETWEeN ENVIRONMENTAL change and human societies have a long and complex history, spanning many millennia.They vary greatly through time and from place to place. Despite these spatial and temporal differences, in recent years a global perspective has begun to emerge that forms the framework for a growing body of research within the environmental sciences. Crucial to the emergence of this perspective has been the dawning awareness of two fundamental aspects of the nature of the planet. The first is that the Earth itself is a single system, within which the biosphere is an active, essential component. In terms of a sporting analogy, life is a player, not a spectator. Second, human activities are now so pervasive and profound in their consequences that they affect the Earth at a global scale in complex, interactive and accelerating ways; humans now have the capacity to alter the Earth System in ways that threaten the very processes and components, both biotic and abiotic, upon which humans depend.

Systems thinking and its application to the environment are not new. However, until very recently, much of the understanding about how the Earth operates was applied to only pieces 
(subcomponents) of the Earth. What is really new about the understanding of the Earth System over the last $10-15$ years is a perspective that embraces the System as a whole. Several developments have led to this significant change in perception:

- The view of Earth from a spaceship, a bluegreen sphere floating in blackness, triggers emotional feelings of a home teeming with life set in a lifeless void, as well as more analytical perceptions of a materially limited and selfcontained entity.

- Global observation systems allow the application of concepts that were only previously applicable at subsystem level, or regional or local scales, to the Earth as a whole.

- Global databases allow global scale phenomena to be addressed with consistently acquired data that have the potential for harmonization and comparison at a global scale.

- Dramatic advances in the power to infer characteristics of Earth System processes in the past allow contemporary observations to be viewed in a coherent time continuum.

- Enhanced computing power makes possible not only essential data assimilation, but increasingly sophisticated models improve understanding of functional interactions and system sensitivities.

Science has crossed the threshold of a profound shift in the perception of the human-environment relationship, operating across humanity as a whole and at the scale of the Earth as a single system.

\section{The Earth as a system}

The fact that the Earth behaves as a single, interlinked, self-regulating system was put into dramatic focus in 1999 with the publication of the 420,000-year record from the Vostok ice core (Fig.1). These data, arguably among the most important produced by the scientific community in the $20^{\text {th }}$ century, provide a powerful temporal context and dramatic visual evidence for an integrated planetary environmental system.

The Vostok ice core data give a wealth of insights into the Earth System. Three striking characteristics demonstrate beyond any doubt that the Earth is a system, with properties and behaviour that are characteristic of the System as a whole.

- The temporal dynamics of global temperature and of the global carbon cycle, as represented by the atmospheric concentration of the trace gases

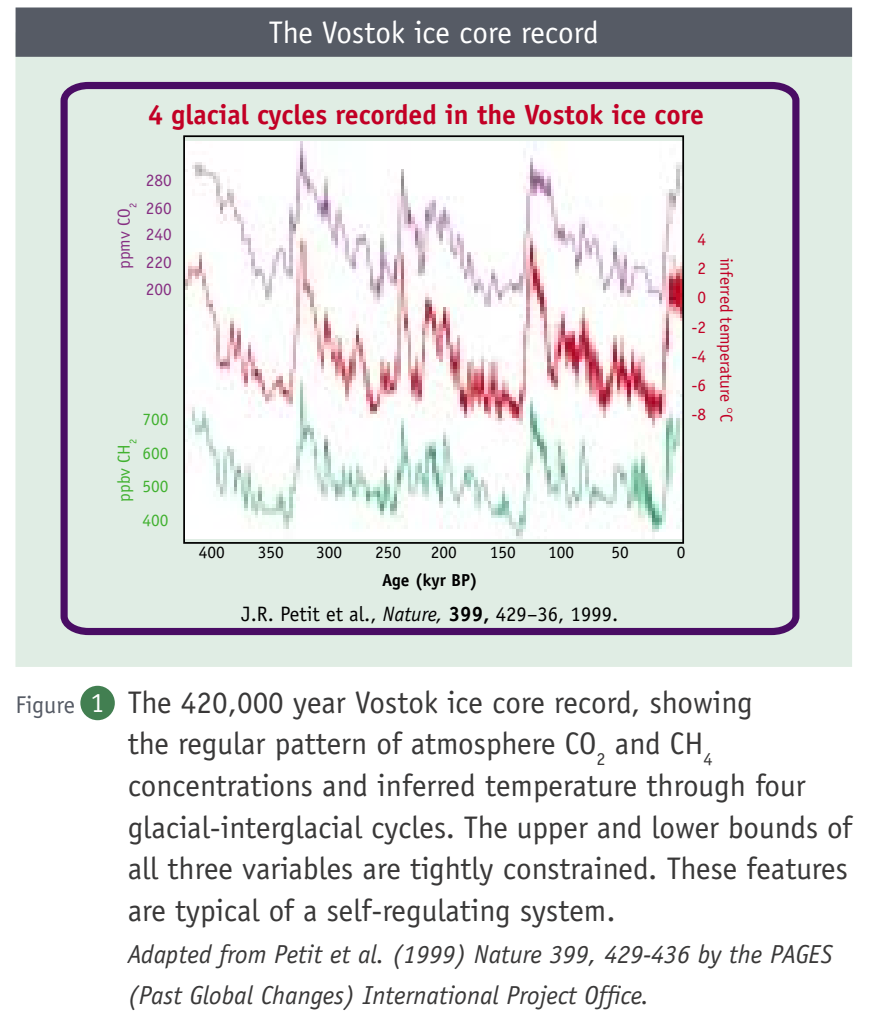

carbon dioxide $\left(\mathrm{CO}_{2}\right)$ and methane $\left(\mathrm{CH}_{4}\right)$, are tightly coupled and show very similar patterns throughout the record.

- The main maxima and minima of temperature and atmospheric trace gas concentration follow a regular pattern through time, each cycle spanning approximately 100,000 years.

- The range over which temperature and trace gas concentrations varied is bounded at upper and lower limits; the values fall recurrently within the same envelope through four cycles of the Earth System over the last half million years.

This systemic behaviour of Earth's environment is due to a combination of external forcing - primarily variations in solar radiation levels near the Earth's surface - and a large and complex array of feedbacks and forcings within Earth's environment itself. The internal dynamics of the System, rather than external forcings, undoubtedly keep the planet habitable for life. For example, without the thin layer of ozone in the upper atmosphere, much more harmful ultraviolet radiation would penetrate to the Earth's surface; and without the thin layer of heat-absorbing greenhouse gases in the lower atmosphere, the planet's mean surface temperature would be about $33^{\circ} \mathrm{C}$ lower than it is now. 


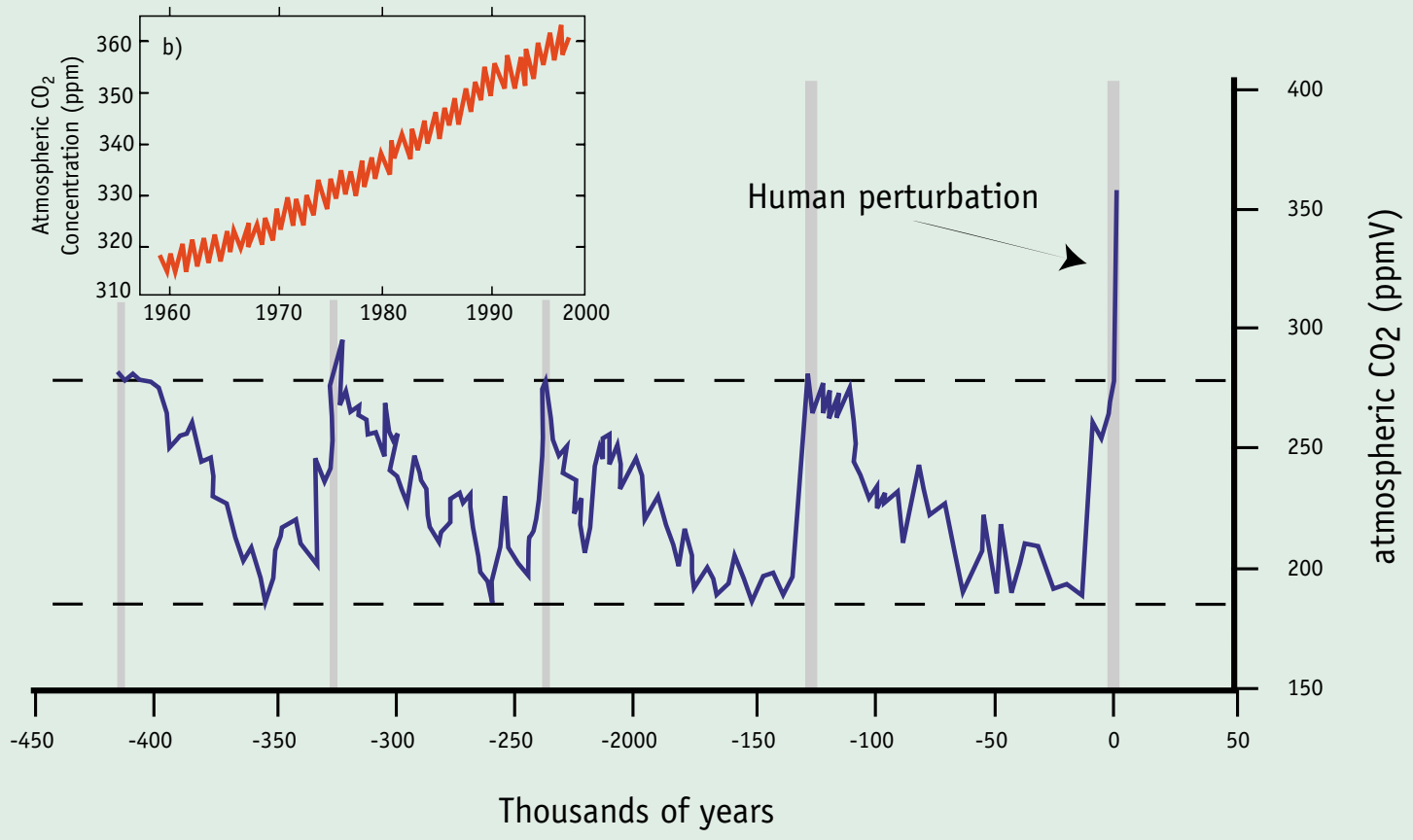

Figure (2) Atmospheric $\mathrm{CO}_{2}$ concentration from the Vostok ice core record with the recent human perturbation superimposed. The inset shows the observed contemporary increase in atmospheric $\mathrm{CO}_{2}$ concentration from the Mauna Loa (Hawaii) Observatory. Sources: Petit et al. (1999) Nature 399, 429-436 and National Oceanic and Atmospheric Administration (NOAA), USA

\section{Global Change}

Over the past few decades, evidence has mounted that planetary-scale changes are occurring rapidly. These are, in turn, changing the patterns of forcings and feedbacks that characterise the internal dynamics of the Earth System (Figs. 2,3). Key indicators, such as the concentrations of $\mathrm{CO}_{2}$ in the atmosphere, are changing dramatically, and in many cases the linkages of these changes to human activities are

\section{0 years of climate change}

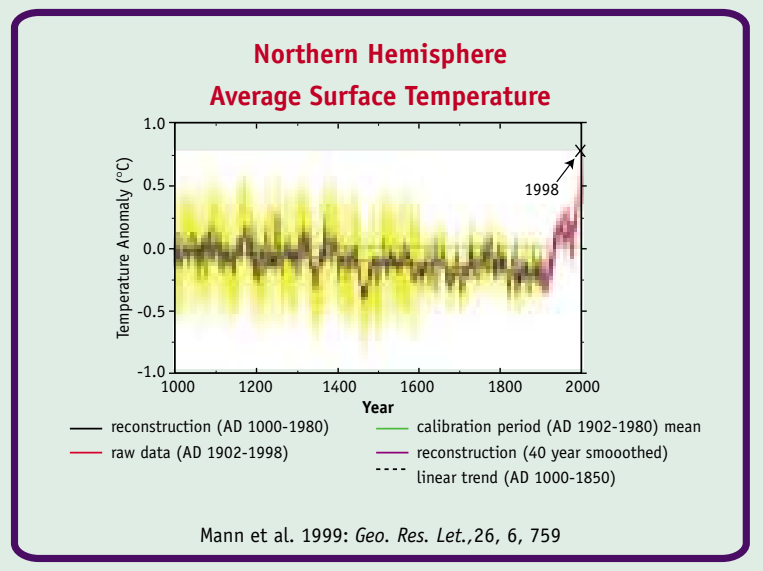

Figure 3 Mean annual temperature variations over the northern hemisphere for the last 1000 years. strong. It is increasingly clear that the Earth System is being subjected to an ever-increasing diversity of new planetary-scale forces that originate in human activities, ranging from the artificial fixation of nitrogen and the emission of greenhouse gases to the conversion and fragmentation of natural vegetation and the loss of biological species. It is these activities and others like them that give rise to the phenomenon of global change.

\section{Box 1: Global change is more than climate change}

The term Earth System refers to the suite of interacting physical, chemical, biological and human processes that transport and transform materials and energy and thus provide the conditions necessary for life on the planet. Climate refers to the aggregation of components of weather - precipitation, temperature, cloudiness, for example - but the climate system includes processes involving ocean, land and sea ice in addition to the atmosphere. The Earth System encompasses the climate system, and many changes in Earth System functioning directly involve changes in climate. However, the Earth System includes other components and processes, biophysical and human, important for its functioning. Some Earth System changes, natural or human-driven, can have significant consequences without involving any changes in climate. Global change should not be confused with climate change; it is significantly more. 


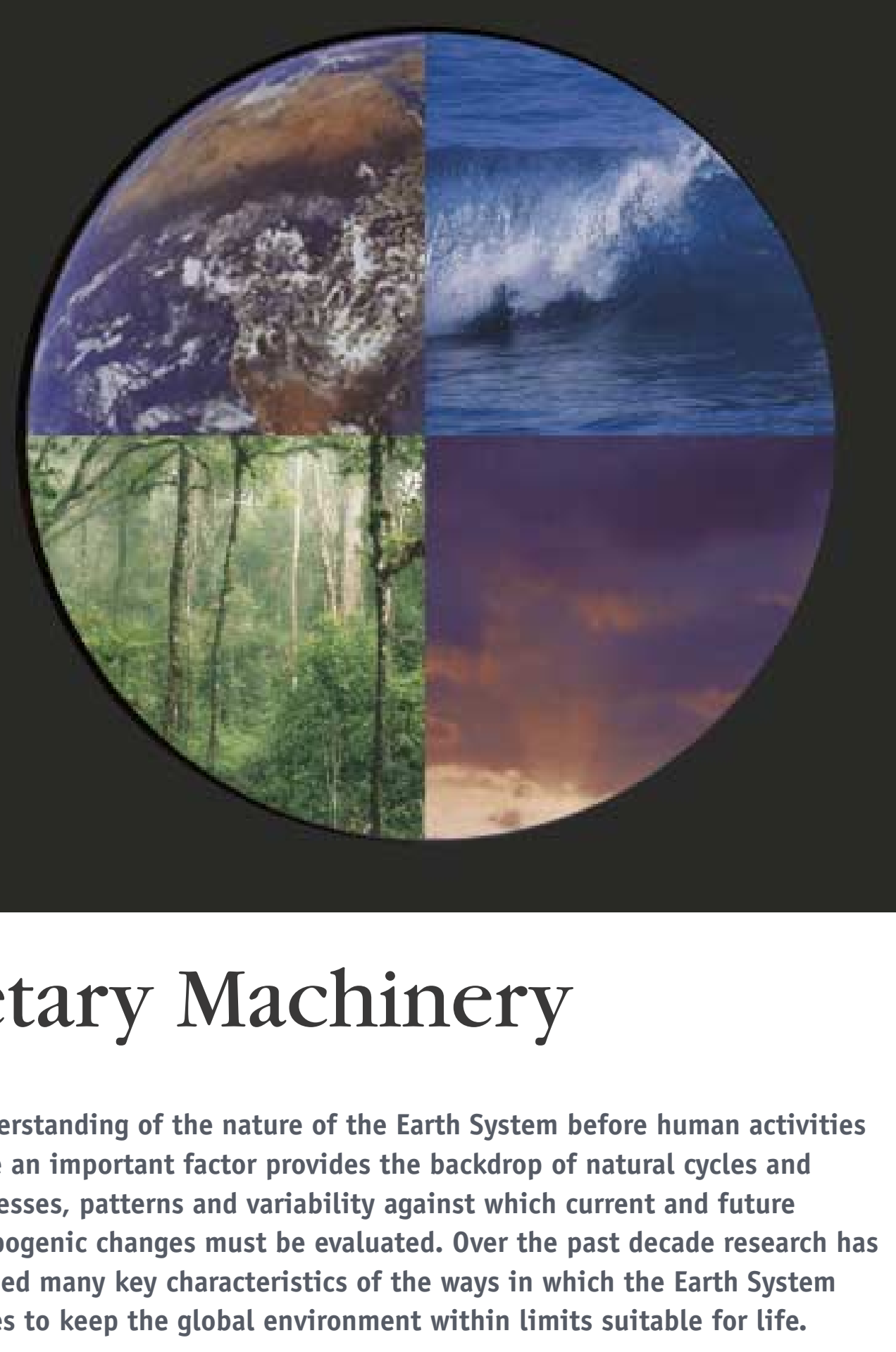

An understanding of the nature of the Earth System before human activities became an important factor provides the backdrop of natural cycles and of processes, patterns and variability against which current and future anthropogenic changes must be evaluated. Over the past decade research has identified many key characteristics of the ways in which the Earth System operates to keep the global environment within limits suitable for life.

\section{Role of the biosphere}

BIOLOGICAL PROCESSES INTERACT STRONGLY with physical and chemical processes to create the environment that keeps Earth habitable for life.The more that the functioning of the Earth System is examined in detail, the greater is the realisation of the role played by life itself in helping to control the System. For example, biological processes contribute significantly to the absorption of atmospheric $\mathrm{CO}_{2}$ by the oceans, which in turn controls atmospheric $\mathrm{CO}_{2}$ concentration on long time scales. Photosynthesis by phytoplankton reduces the amount of $\mathrm{CO}_{2}$ in the surface layer of the ocean, thereby allowing more $\mathrm{CO}_{2}$ to dissolve from the atmosphere. About $25 \%$ of the carbon fixed by phytoplankton in the upper layers sinks to the interior, where it is stored away from contact with the atmosphere for hundreds or thousands of years. This biological pump, along with physico-chemical constraints on the solubility of $\mathrm{CO}_{2}$, control the pattern of $\mathrm{CO}_{2}$ exchange between the oceans and the atmosphere. Intriguingly, the nature of the phytoplankton species involved in the biological pump may hold a key to the rate of and potential for carbon storage (Fig. 4).

Terrestrial biota are also an important component in Earth System functioning in a number of ways. For example, the type of vegetation present on the land surface influences the amount of water transpired 


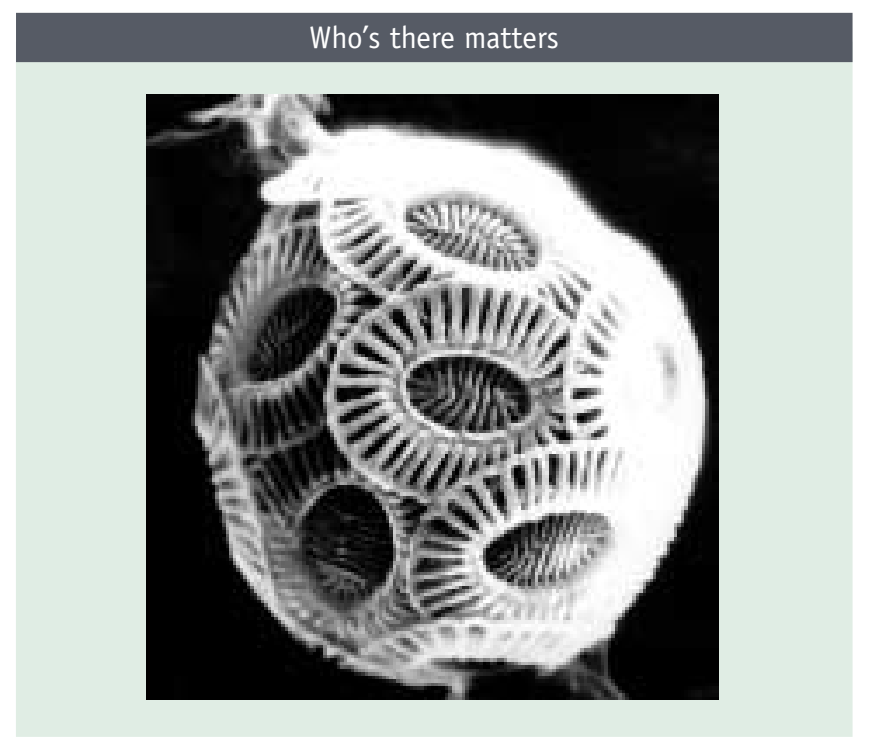

Figure 4 Life in the oceans plays an important role in maintaining geochemical balance in the Earth System and the fate of the carbon that is fixed by the ocean's phytoplankton is very much a function of the size and taxonomy of the species present. For example, in addition to fixing carbon via photosynthesis, one group of phytoplankton, the coccolithophorids, such as Emiliania huxleyi (shown above) produces calcium carbonate platelets (liths). Each lith is only about $2.5 \mu \mathrm{m}$ in length but many are produced every year. It is estimated that blooms of $E$. huxleyi cover about 1.4 million $\mathrm{km}^{2}$ of the ocean every year. Thus, over geological time, tremendous accumulations of carbon fixed by coccolithophorids develop. The white cliffs of Dover are, for example, largely comprised of platelets from coccolithophorids. Source: K. Richardson.

back to the atmosphere and the absorption or reflection of the sun's radiation. The vegetation's rooting patterns and activity are also important controllers of both carbon and water storage and of fluxes between the land and the atmosphere. The biological diversity of terrestrial ecosystems affects the magnitude of key ecosystem processes such as productivity, and plays a role in the long-term stability of ecosystem functioning in the face of a changing environment.

\section{Temporal variability}

Variability and change are realities of the Earth System, and static, so-called equilibrium, conditions are unlikely to be a part of the System on almost any time scale. The notion that unusally stable conditions prevailed over the past several millenia, when human civilisations developed, and represent normal conditions is false. The record shows that the functioning of the Earth System has varied continuously on all time-scales (Fig. 5). A careful examination of evidence from the past shows that:

- variability is reflected not only in temperature - variability in the hydrological cycle, which is often of much greater importance to human populations, has been quite extreme on all time-scales in the past,

- no single variable or region truly reflects global variability - global mean conditions mask immense variations in regional responses,

- during the late Holocene, when the natural forcings and boundary conditions were similar to those operating today, there is strong evidence that the range of variability significantly exceeded that captured by instrumental records. Reliance on the very short period of instrumental records gives a false sense of the true variability of the Earth System.

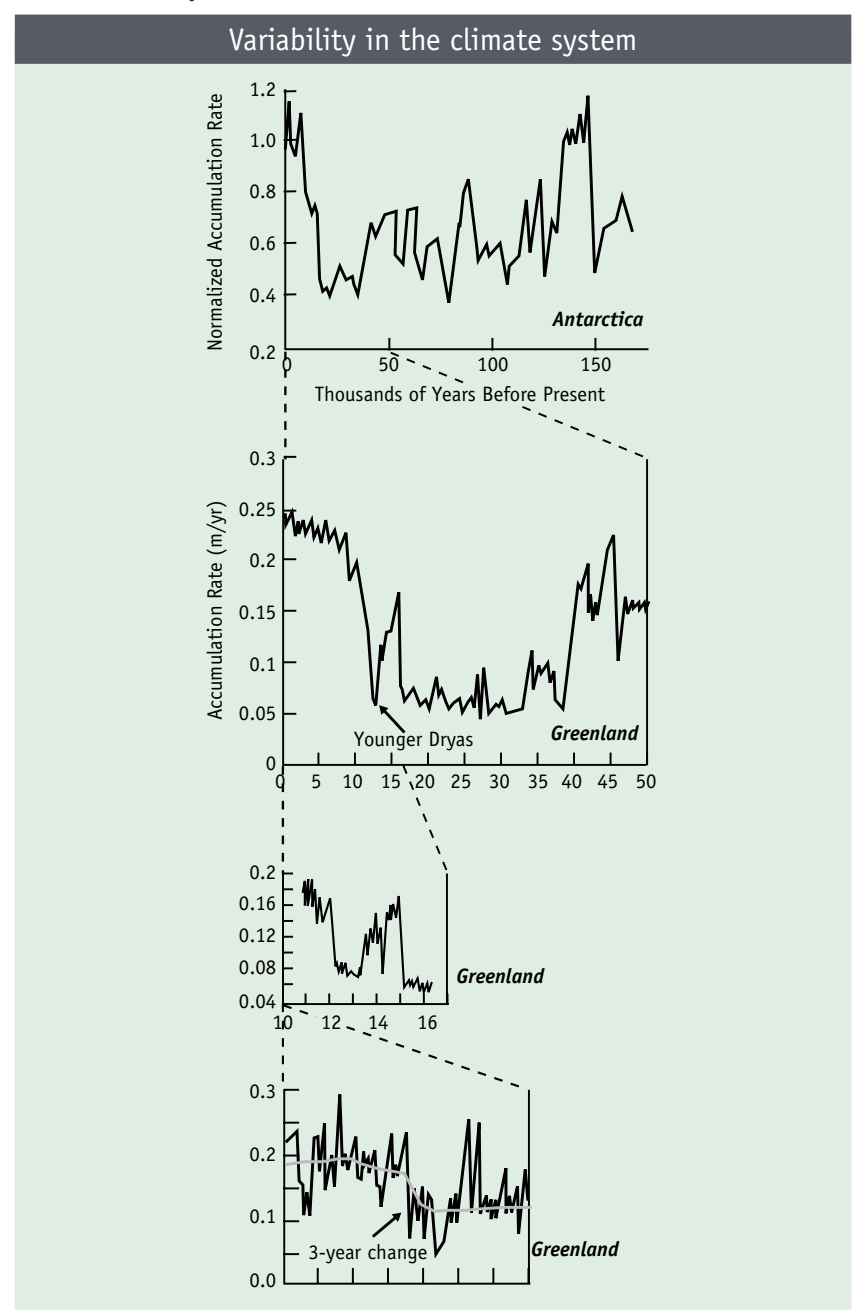

Figure 5 Variability in the climate system. Ice accumulation rate history at four different time scales. Data from Antarctica (top panel) and Greenland (bottom three panels).

Adapted from Jacobson et al. (eds.) (2000) Earth System Science, Academic Press, p. 479. 


\section{Linkages and connectivities}

One of the most ubiquitous features of the planetary machinery is the suite of linkages that bind processes in one region to consequences in others thousands of kilometers away. Atmospheric and oceanic circulation play a major role in the transport of heat from the tropics to the poles. The horizontal movement of water in rivers is another important transport process that couples seemingly isolated parts of the planet.

The atmospheric transport of materials, often considered only in the context of air pollution, also plays a role in natural biogeochemical cycles by linking land and ocean processes across long distances. In southern Africa, for example, recirculating air flows pick up dust from arid lands and smoke from industrial areas and eventually transport them over the southern Indian Ocean towards Australia. Portions of these plumes subside regularly over certain patches in the ocean, depositing iron-laden dust on the sea surface. The iron, a micro-nutrient for phytoplankton, probably acts as an intermittent fertiliser triggering planktonic blooms and accounting for the observed 'hot spots' of carbon uptake in precisely these areas of the southern Indian Ocean (Fig. 6).

Horizontal transport of materials also occurs via river networks, which provide corridors that link mountains and coastal areas, land and water ecosystems, across landscapes regional to subcontinental in scale. Riverine fluxes have been a

major pathway by which carbon, phosphorus, and other elements cycle on geologic timescales. Prior to significant human disturbance, nutrient cycling in terrestrial ecosystems was usually tightly constrained within the ecosystem itself with much recycling; there was little leakage to river networks. Leakage occurred only when terrestrial nutrient cycles were briefly perturbed by rare events or sequences of rare events.

\section{Abrupt changes and critical thresholds}

Because human societies have developed and flourished over a very short period of time from an Earth System perspective, and because the period of instrumental observation and modern scientific enquiry is even shorter, a narrow view of the Earth's environment has developed.The notion that a single stable equilibrium is the natural state of Earth's environment is not supported by observations of past global changes. The behaviour of the Earth System is typified not by stable equilibria, but by

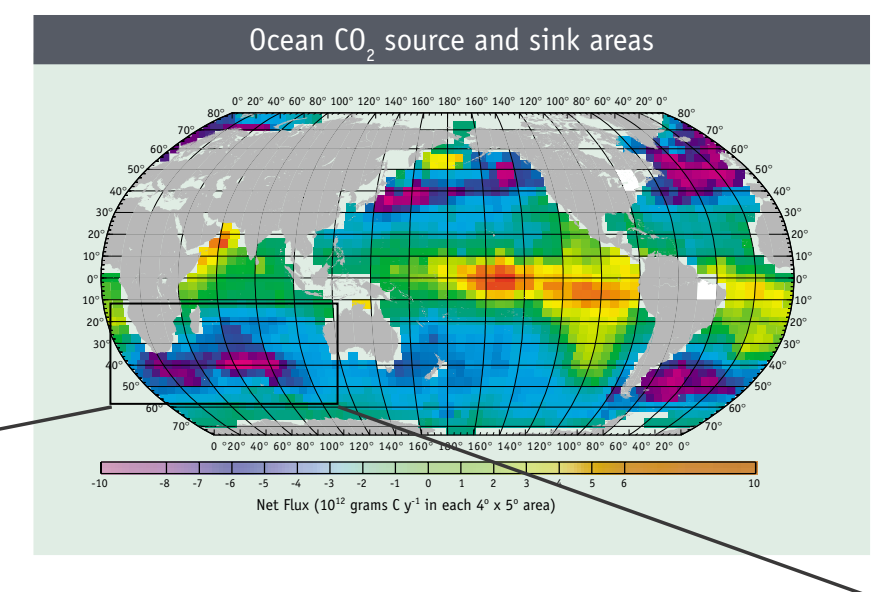

Iron deposition on the south Indian Ocean $\mathrm{CO}_{2}$ sinks

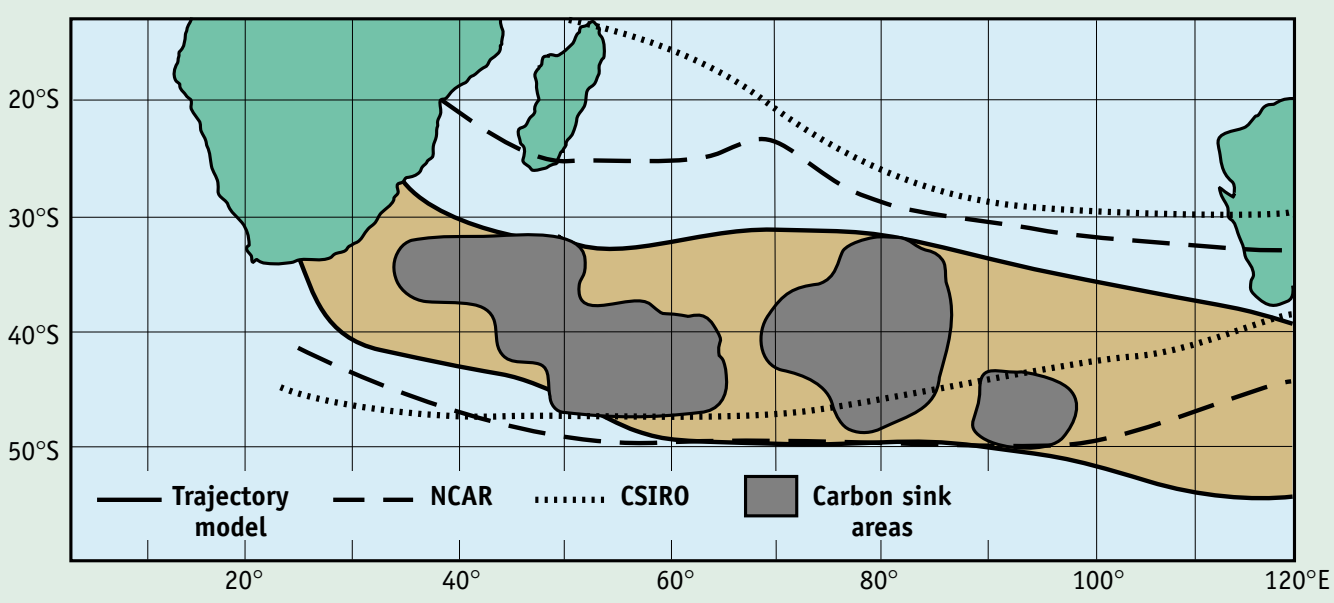

Figure 6 Top panel: Mean annual exchange of $\mathrm{CO}_{2}$ across the sea surface. Blue and purple colours denote regions in which the ocean takes up large amounts of $\mathrm{CO}_{2}$. Bottom panel: The trajectory of iron-laden aerosols from southern Africa over the southern Indian Ocean and their deposition on areas of observed carbon uptake.

Sources: Takahashi et al. (1999) Proc. $2^{\text {nd }}$ Intl. Symp. on CO in Oceans, pp. 9-15. Piketh et al. (2000) Sth. Afr. J. Sci. 96, 244-246. 

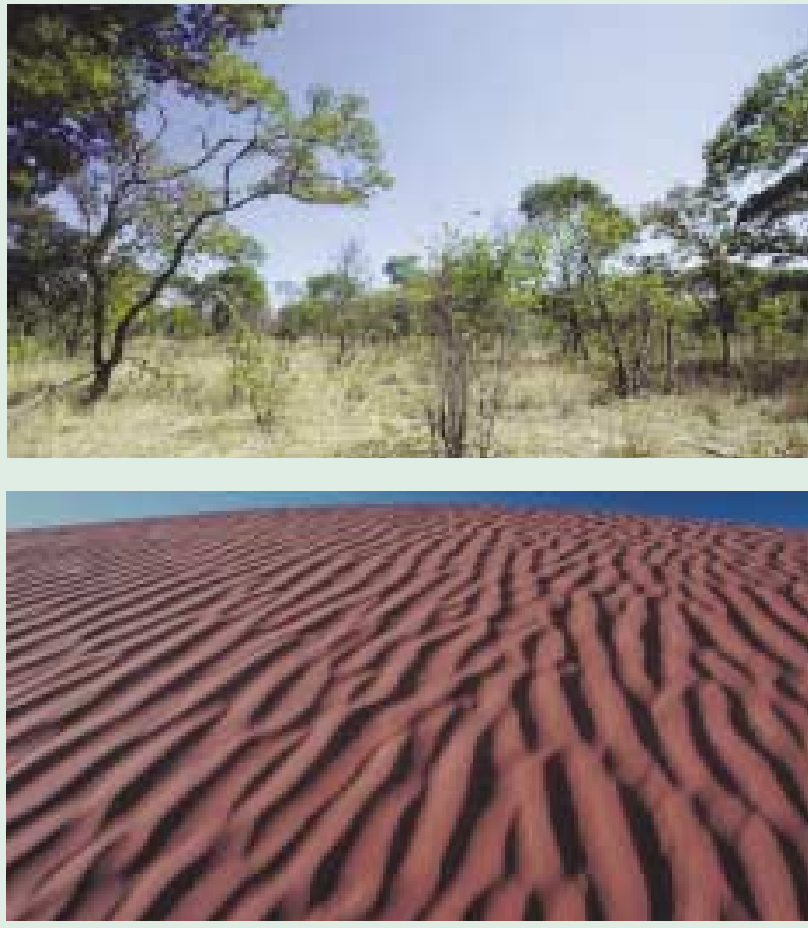

The dramatic desertification of the Sahelian region in prehistoric times demonstrates several important features of Earth System functioning. About 6000 years ago the climate in the Sahel-Sahara region was much more humid than today, with vegetation cover resembling that of a modern-day African savanna. About 5500 years ago, an abrupt change in the regional climate occurred, triggering a rapid conversion of the Sahara into its present desert condition.

The ultimate cause was a small, subtle change in Earth's orbit, leading to a small change in the distribution of solar radiation on Earth's surface (part a of figure). Model simulations suggest that this small change nudged the Earth System across a threshold that triggered a series of biophysical feedbacks that led, in turn, to a drying climate (part b).

Vegetation changed more sharply in response to changing
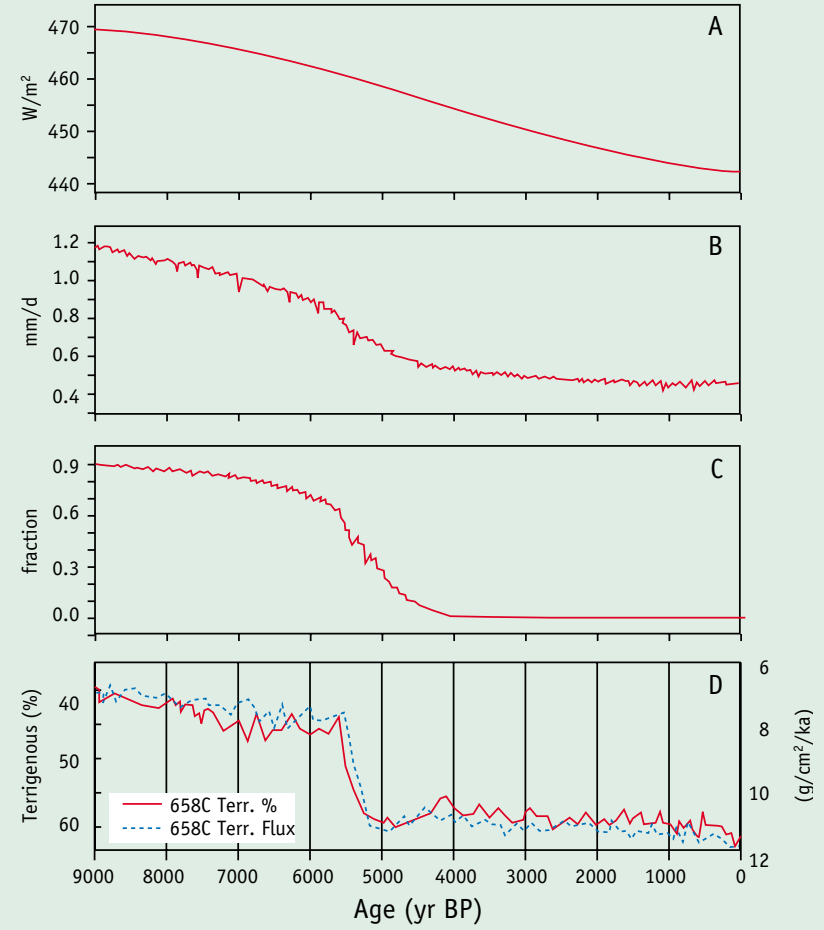

rainfall (part c), and the region became the present-day desert. Model predictions of the resulting increase in wind erosion and deposition of sand off the West African coast agree remarkably well with observations (part d).

The model simulations suggest that it was an interplay of atmosphere, ocean, vegetation and sea ice changes in widely separated parts of the planet that amplified the original orbital forcing. The abrupt change from savanna to desert in North Africa demonstrates that (i) abrupt changes can occur when thresholds are crossed, (ii) the biosphere plays a critical role in Earth System functioning, and (iii) teleconnections are an essential feature of the planetary machinery.

Photos: D. Parsons. Figure from Claussen et al. (1999) 24, 2037-2040 and deMenocal et al. (2000) Quat. Sci. Rev. 19, 347-361.

especially in lower latitudes,

- the changes demonstrate widespread spatial coherence, but are not always globally synchronous, and

- complex inter-hemispheric leads and lags occur that require feedback mechanisms for amplifying and propagating changes in both space and time.

In terms of the present and future, these observations are especially important. They raise the possibility that antbropogenically induced global change could trigger sudden, dramatic switches in climate and other components of the Earth System comparable to those that have occurred in the past. 


\title{
The Anthropocene Era
}

\author{
Human activities now significantly influence the workings of the \\ planetary machinery. Human changes to the Earth System are multiple, \\ complex, interacting, often exponential in rate and globally significant \\ in magnitude. Humankind has become a forceful, if not controlling, \\ component in the functioning of the Earth System.
}

\section{The nature of global change}

UNTIL VERY RECENTLY IN the history of Earth, humans and their activities have been an insignificant force in the dynamics of the Earth System. Today, humankind has begun to match and even exceed nature in terms of changing the biosphere and impacting other facets of Earth System functioning (Fig. 7).The magnitude, spatial scale, and pace of human-induced change are unprecedented. Human activity now equals or surpasses nature in several biogeochemical cycles. The spatial reach of the impacts is global, either through the flows of the Earth's cycles or the cumulative changes in its states. The speed of these changes is on the order of decades to centuries, not the centuries to millennia pace of comparable change in the natural dynamics of the Earth System.
The extent to which human activities are influencing or even dominating many aspects of Earth's environment and its functioning has led to suggestions that another geological epoch, the Antbropocene Era (Paul Crutzen and Eugene Stoermer have coined the term Anthropocene to describe the present era, in which human activities have become a significant force in the dynamics of the Earth System), has begun:

- in a few generations humankind is in the process of exhausting fossil fuel reserves that were generated over several hundred million years,

- nearly $50 \%$ of the land surface has been transformed by direct human action, with significant consequences for biodiversity, nutrient cycling, soil structure and biology, and climate, 
- more nitrogen is now fixed synthetically and applied as fertilizers in agriculture than is fixed naturally in all terrestrial ecosystems.

- more than half of all accessible freshwater is used directly or indirectly by humankind, and underground water resources are being depleted rapidly in many areas.

- the concentrations of several climatically important greenhouse gases, in addition to $\mathrm{CO}_{2}$ and $\mathrm{CH}_{4}$, have substantially increased in the atmosphere,

- coastal and marine habitats are being dramatically altered; $50 \%$ of mangroves have been removed and wetlands have shrunk by one-half.

- About 22\% of recognized marine fisheries are overexploited or already depleted, and $44 \%$ more are at their limit of exploitation,

- Extinction rates are increasing sharply in marine and terrestrial ecosystems around the world; the Earth is now in the midst of its first great extinction event caused by the activities of a single biological species (humankind).

\section{Drivers of change}

Over the past two centuries, both the human population and the economic wealth of the world have grown rapidly. These two factors have increased resource consumption significantly, evident in agriculture and food production, industrial development, international commerce, energy production, urbanisation and even recreational activities. These are just some of the enterprises transforming the Earth System.

Around 6 billion people inhabit the globe at present. All share basic human needs, such as the demand for water, food, shelter, community health and employment.The ways in which these needs are met are critical determinants of the environmental consequences at all scales (Table 1). In the developed world affluence, and more importantly the demand for consumer goods for entertainment, for mobility, for communication and a broad range of goods and services, is placing significant demands on global resources. Between 1970 and 1997, the global consumption of energy increased by $84 \%$, and consumption of materials also increased dramatically.

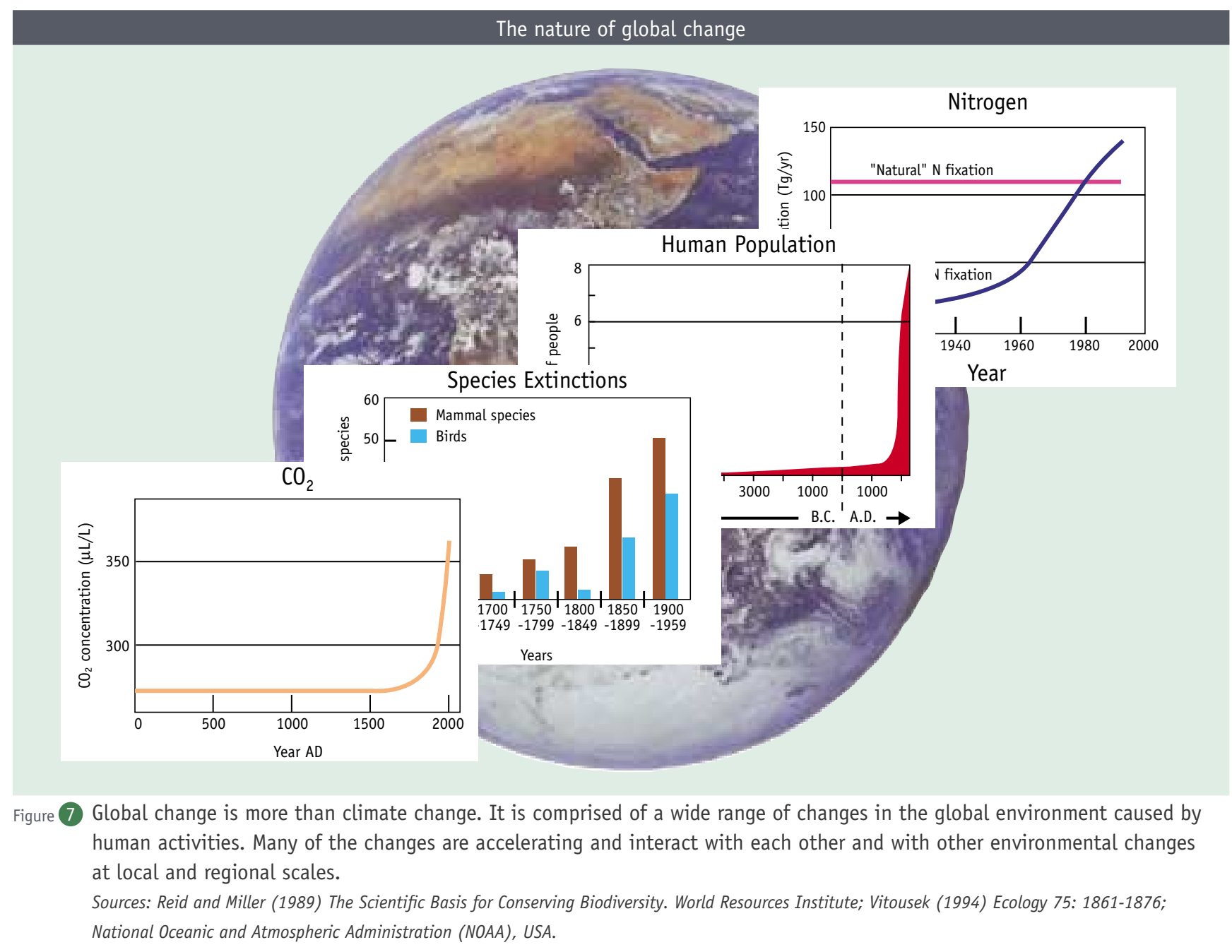




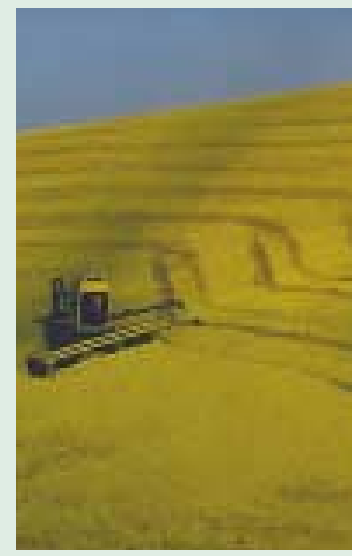

Compartment/

Cycle Transformed Proximate Driver

Clearing (cutting forest, + burning), agricultural practices (e.g. tillage, fertilisation, irrigation, pest control, highyielding crops etc.), abandonment

UNDERLYing DRIVER

Demand for food (+dietary preferences), recreation, other ecosystem goods and services

Atmosphere Fossil fuel burning, landuse change (e.g., agricultural practices), biomass burning, industrial technology

Dams, impoundments, reticulation systems, waste disposal techniques, management practices

Demand for mobility, consumer products, food

Water

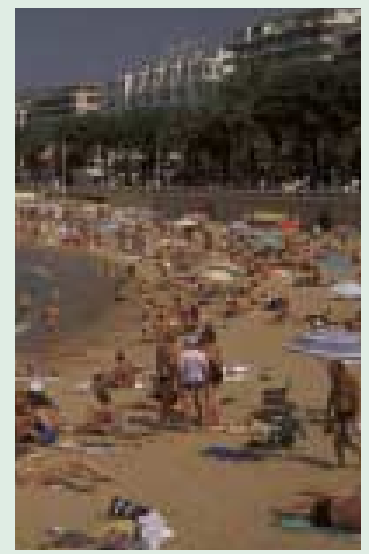

\section{Coastal/Marine Land-cover conversion,} groundwater removal, fishing intensity \& technique, coastal building patterns, sewage treatment technology, urbanisation

Biodiversity Clearing of forest/natural ecosystems; introduction of alien species

Demand for food, safety, comfort, landscape amenity

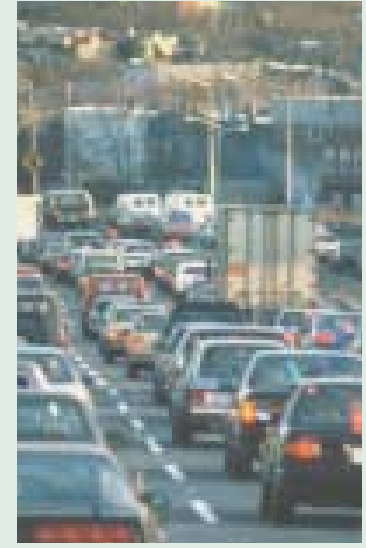

Demand for water (direct human use), food (irrigation), consumer products (water usage in industrial processes) Demand for recreation, lifestyle, food, employment
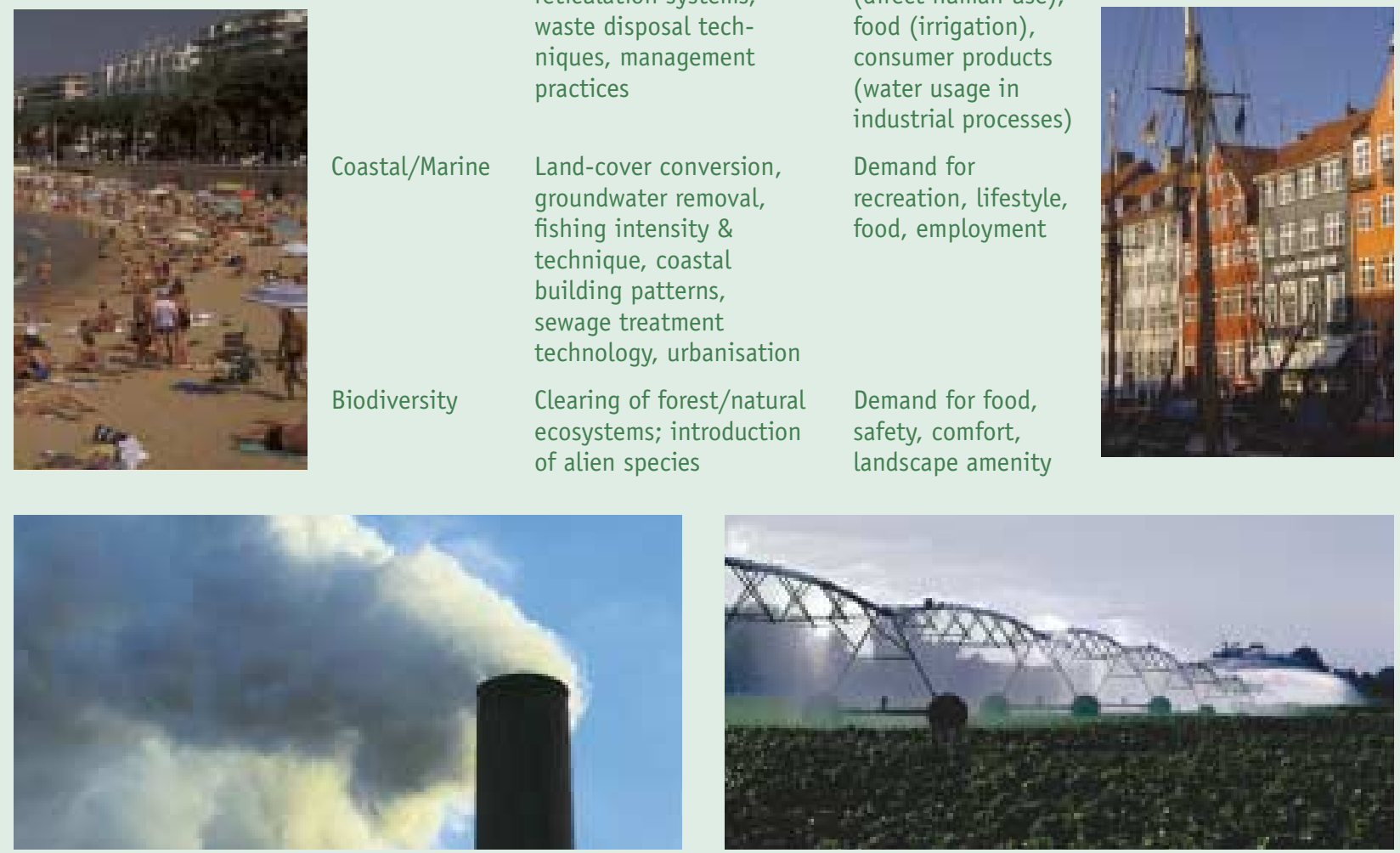

1 Proximate and underlying drivers of human transformation of Earth. Proximate drivers are the immediate human activities that drive a particular environmental change; underlying drivers are related to the fundamental needs and desires of individuals and groups. Proximate and underlying drivers are the end points in a linked sequence with numerous intermediate linkages markets, institutions, infrastructure, policy, political systems, cultural values.

While the global population more than doubled in the second half of the last century, grain production tripled, energy consumption quadrupled, and economic activity quintupled. Although much of this accelerating economic activity and energy consumption occurred in developed countries, the developing world is beginning to play a larger role in the global economy and hence is having increasing impacts on resources and environment.

Energy is needed for almost all activities in all countries, industrialised and industrialising. Much is derived from the combustion of fossil fuels, which leads to emissions of $\mathrm{CO}_{2}$, other trace gases and aerosols. Industrialisation has led to considerable air and water pollution associated with the extraction, production, consumption and disposal of goods. Over 100,000 industrial chemicals are in use today and the number is increasing rapidly in the expanding agricultural, metals, electronics, textiles and food industries. Some of these chemicals can have significance for the functioning of the Earth System. 
Over the past three centuries, the amount of land used for agriculture has increased five-fold. Furthermore, large areas of land area have been lost to degradation, due, for example, soil erosion, chemical contamination and salinisation. Although the increase in agricultural yields due to application of fertilisers, pesticides and irrigation has been of essential benefit to humankind, the negative consequences for the Earth System have been considerable. These include major alterations to ecosystem functioning, interference in the nitrogen and phosphorous cycles, changes of species diversity, loss of soil organic matter and soil erosion. Changes in marine ecosystems as a result of human activities are no less significant.

As the 21st century unfolds, population, development, affluence, and technology are set to interact in ways that will have important implications for the Earth System. Unless many of the trends of the $20^{\text {th }}$ century are slowed significantly or reversed, the pressure on the planetary environment will increase even further. Strategies will have to be found to ensure the sustainability of the Earth System while accommodating economic and social development.

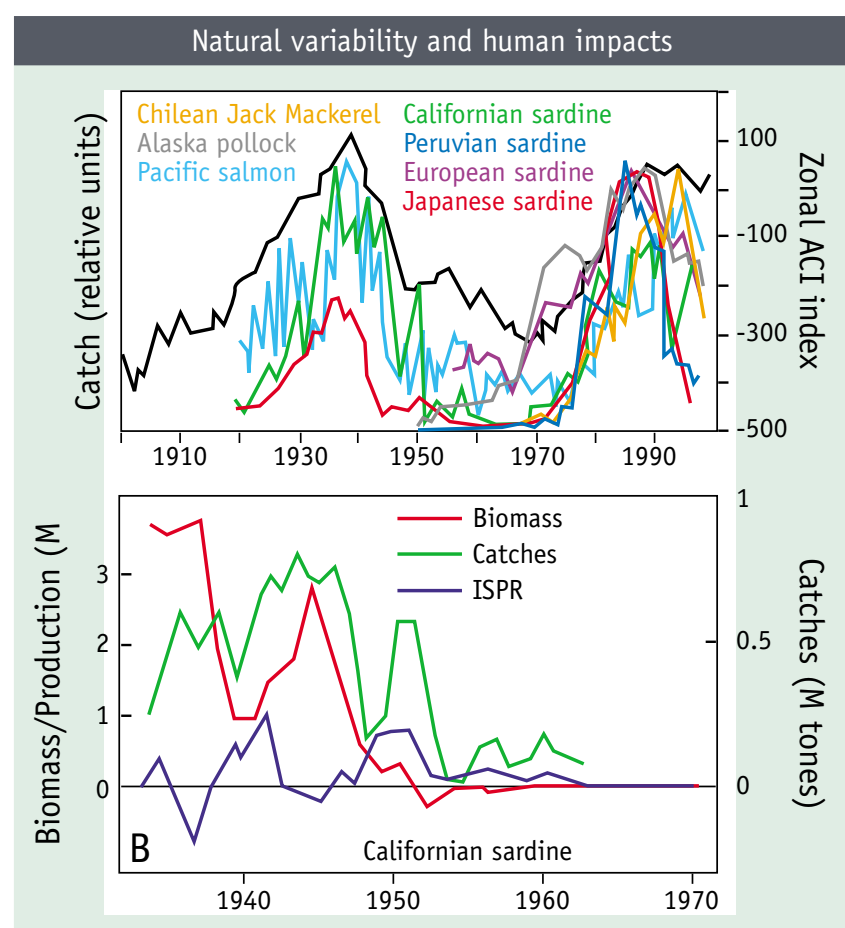

Figure 8 Top panel: Correlation between catch trends in some major commercial fish species and dynamics of the Atmospheric Circulation Index (ACI), a measure of climate variability. Bottom panel: Dynamics of Californian sardine stocks, showing the stock collapse due to overfishing in the 1940s.

Source: GLOBEC (Global Ocean Ecosystem Dynamics) International Project Office.

\section{An Earth System perspective}

The implications of human activities for the Earth System become apparent when the myriads of smaller human-driven changes are aggregated globally over long periods of time, influencing Earth System functioning as a global scale force in their own right. Several properties of this new force emerge as important features of an altered Earth System.

Just as connections in the biophysical part of the Earth System link processes across long distances, socio-economic and cultural connections link human activities in widely separated regions of the planet. Urban areas, for instance, depend on large hinterlands to satisfy their population's demands for food, fibre, water and other ecosystem goods and services. On a larger scale, the phenomenon of globalisation is equally profound. Investment, industrialisation, commercialisation and economic activity in general are increasingly operating across national boundaries and institutions in a growing global system. Investment decisions in Europe or North America, for example, can lead to sharp changes in the rate of deforestation in Amazonia, and to the accompanying environmental consequences. Together, urbanisation and globalisation will undoubtedly be profound drivers of environmental change at the global scale for the next several decades at least.

Human-driven changes are not easy to identify and attribute in a cause-effect paradigm; they are superimposed on, and usually interact with, natural patterns of variability in the Earth System. It is thus of paramount importance to disentangle analytically human impacts from natural variability in order to understand their relative importance as drivers of change in Earth System functioning. For instance, are fluctuating fish stocks due to overfishing or to natural variability (Fig. 8)? There is strong evidence to suggest that until the recent past fish stocks were highly correlated with climate variability. However, since the middle of the last century fishing began to exert significant pressure on stocks. The case of the California sardine shows that human pressures can override natural fluctuations. Overfishing in the 1940 s, when sardine stocks were naturally low due to climate variability, led to a stock collapse and an inability to recover when climate became more favourable, a classic case of the interaction of natural variability and human-driven change. 


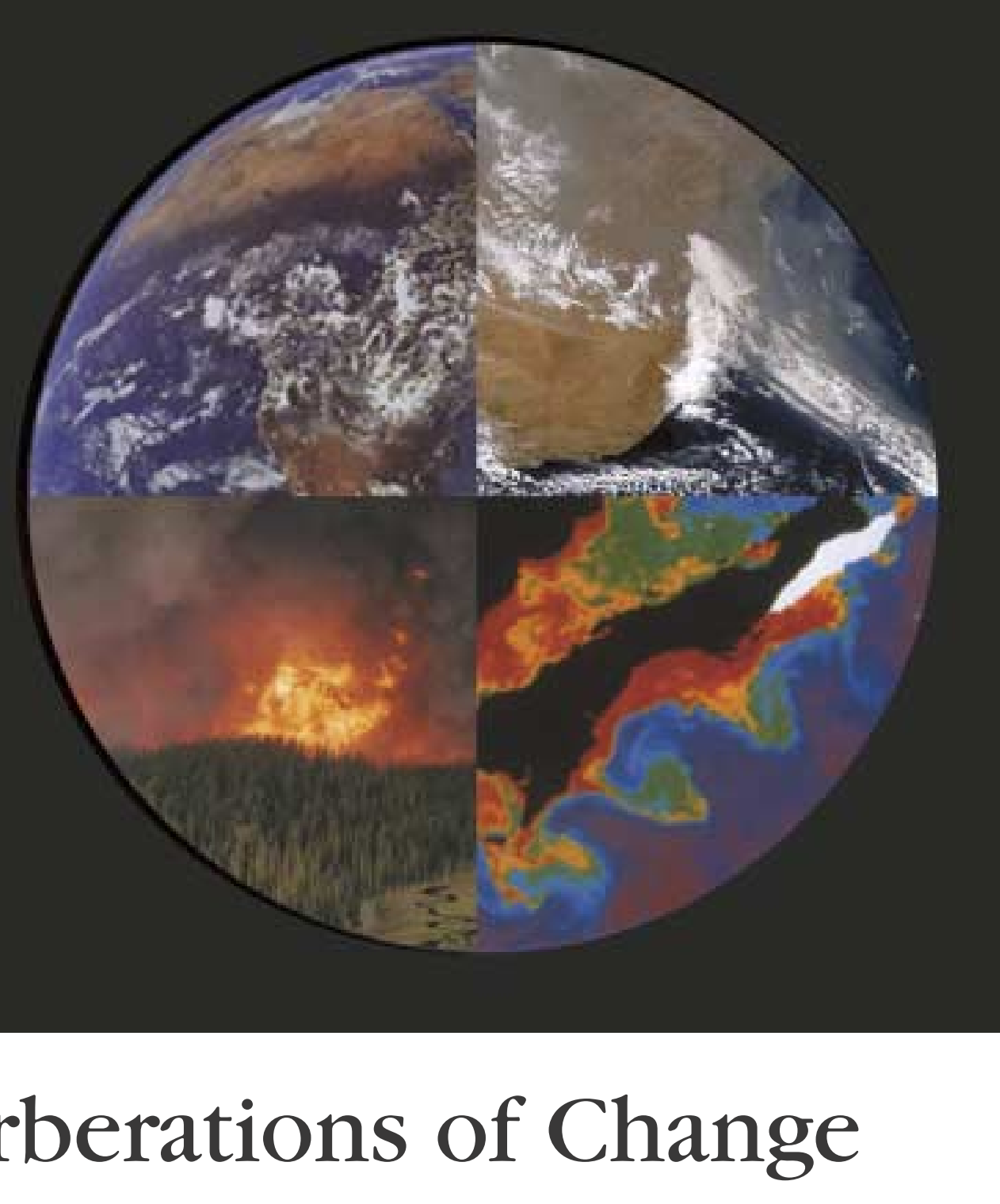

\section{Reverberations of Change}

Human changes to the Earth System do not operate in simple cause-effect relationships. A single type of change triggers a large number of responses in the Earth System, which then reverberate or cascade through the System, often interacting with natural variability to become feedbacks for further change.

\section{Long-term perspectives}

The LEgACY OF PAST human changes to the Earth System provides the backdrop on which the present, much more significant, suite of human changes will be played out. To understand and project what is happening now and in the future, it is essential to understand the long-term cumulative effects of past human impact and the nature of specific environmental thresholds, particularly those that lead to reduced resilience.

The degradation of terrestrial ecosystems by human activities is often linked to a shift beyond a threshold in a critical function, such as productivity. In parts of the New Guinea Highlands, for example, intensification of subsistence farming has led to the conversion of a productive forest-garden mosaic, based on a cycle of forest clearance, subsistence horticulture and woody regeneration, into a stable but much less productive grassland ecosystem.

The Baltic Sea has undergone similar reverberations of change due to human activities around its shores; over the past two centuries dense human populations have sufficiently increased nutrient supplies to the sea to cause a threshold to be passed. Eutrophication occurred, the depth to which light can penetrate decreased and the balance in diatom productivity shifted from benthic (bottom-dwelling) to planktonic communities. To understand future global change-related impacts on contemporary systems like the New Guinea Highlands and the Baltic Sea, the cascading effects of past human-driven changes must be understood. 
Like fossil fuel combustion, the impacts of land-use change reverberate through the Earth System at various scales and in various ways. Land-use change itself is often a complex phenomenon. The initial activity is normally the conversion of a natural ecosystem, such as a forest, to a managed agricultural system. The immediate consequences, such as the loss of carbon to the atmosphere through the burning of the slash, are obvious, but many other effects cascade through the environment at regional and even global scales for years after the initial clearing event.

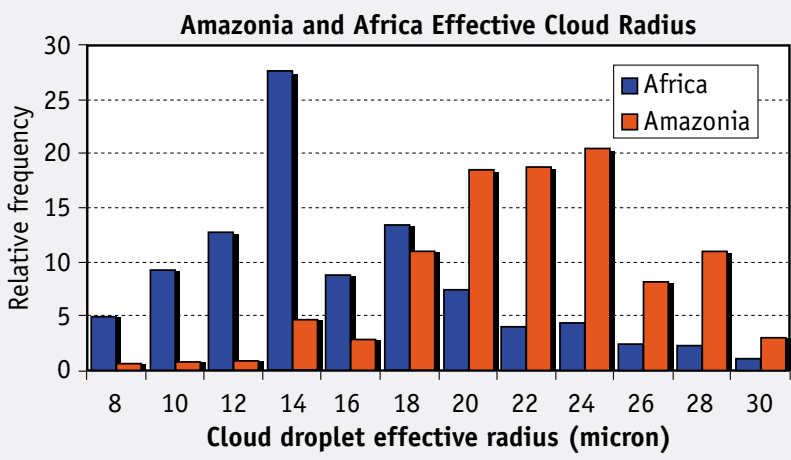

Daniel Rosenfeld AVHRR analysis

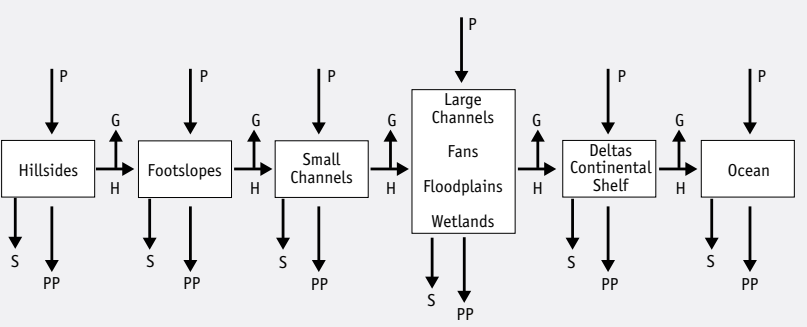

Source: R. Wasson

Land-use change can have direct implications for the Earth System at the global scale through the teleconnections of the climate system. For example, modelling studies suggest that if the land cover of the Amazon Basin changes from predominantly tropical forest to grassland or crops, the atmospheric circulation patterns over the Western Hemisphere at least would change, and this would necessarily cause readjustments to global circulation as a whole.

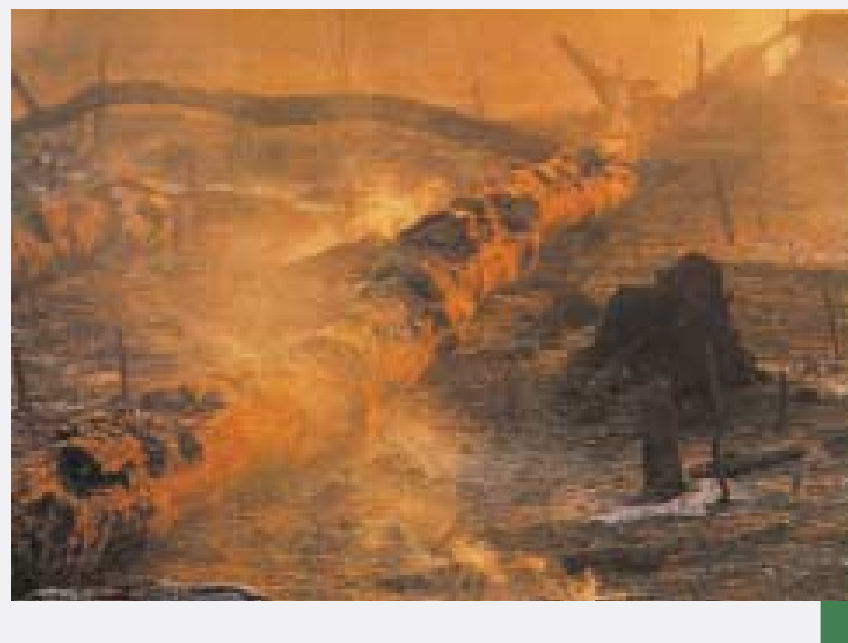

LOCAL

Burning of biomass associated with the clearing of forests in Amazonia can affect local and regional rainfall. Biomass burning, like fossil fuel combustion, produces aerosols of a variety of sizes. Some of the larger particles act as nuclei for condensation and cloud droplet growth to form rain. Smaller particles form smaller cloud droplets that may inhibit rainfall. This appears to be happening over Amazonia; a similar cascading impact of land-use change may be altering rainfall elsewhere, notably over southern Africa.

\section{REGIONAL}

Reverberations of land-use change at the regional scale are ubiquitous, for example, the mobilisation of materials - carbon, nutrients, other substances in both dissolved and particulate form - from landscapes and their transport by runoff and rivers in catchment cascades to the coastal zone. These materials often follow long and complex pathways, undergoing transformations and temporary storage along the way. The eventual impacts on the geomorphology and biogeochemistry of the coastal zone are profound.
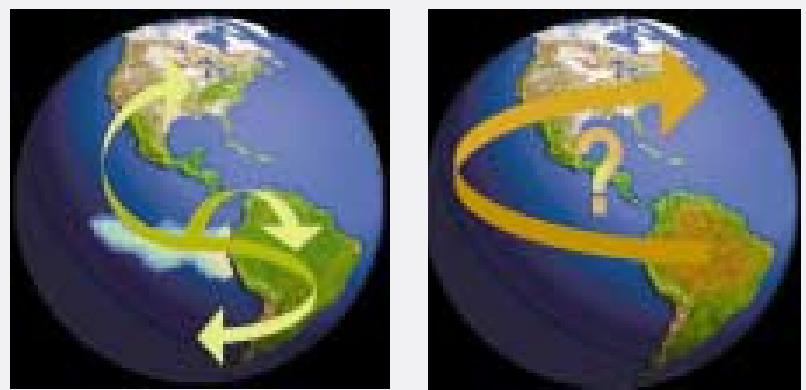

Source: R. Avissar 


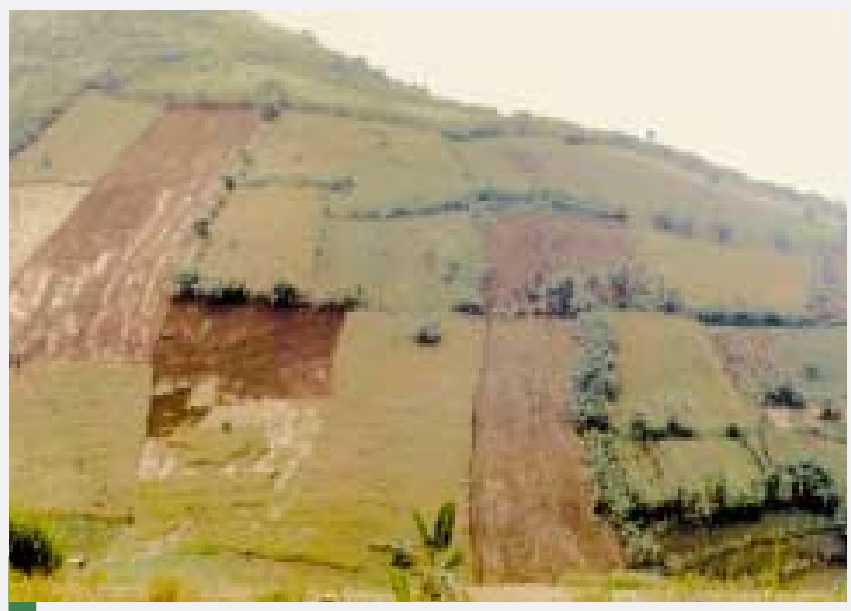

LOCAL

The direct on-site effects of converting a forest to grazing or cropping include the loss of soil organic carbon, via erosion and transport off-site by rivers or via oxidation and loss to the atmosphere. The loss of soil carbon continues for years after the initial clearing and is influenced by the type of agricultural practices that are employed. When aggregated, losses of soil organic carbon have global-scale effects on the carbon cycle.
Land use follows various trajectories after the initial conversion. A common pathway is for less intensive agriculture to be practised initially, followed some years later by intensification - the use of fertilisers, irrigation and pest control, for example - to increase yields. This trajectory will become more common as food demand rises and less land is available for conversion. Intensification modifies the cascading effects of land-cover conversion, damping some but intensifying others, such as the addition and mobilisation of nitrogen compounds and their loss to the atmosphere and to waterways.

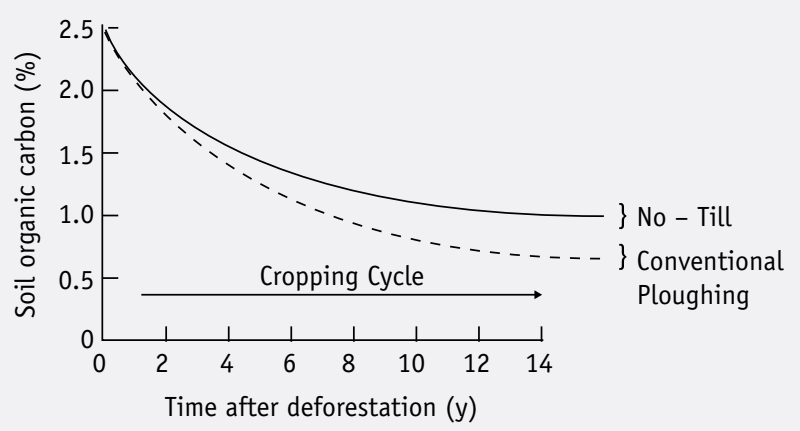

Adapted from K. Paustian et al. (1997) Soil Use and Management 13, 230-244.

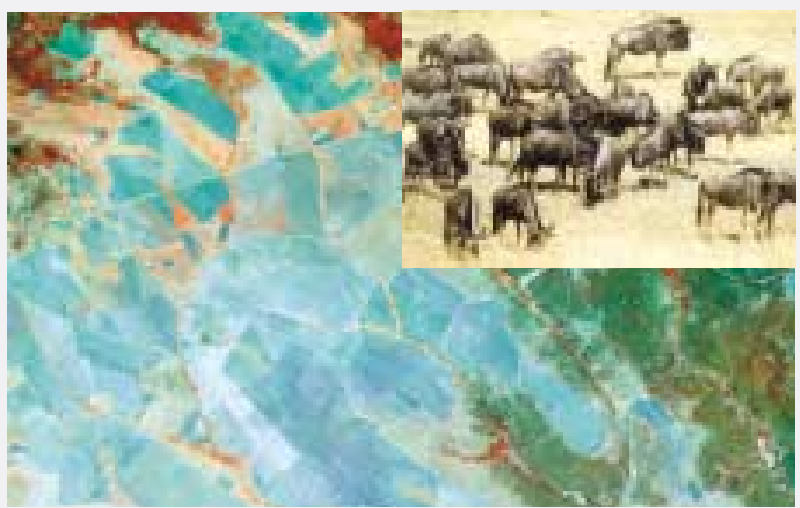

Source: Remote Sensing and Regional Analysis Laboratory, UCLouvain, Belgium and Suzanne Serneels

Biomass burning associated with land clearing and agricultural practices in Southeast Asia is an important regional political issue, but the environmental effects are global. Satellite remote sensing in February 2001 showed strong production of carbon monoxide centred in Thailand, a result of seasonal burning as part of the normal agricultural practices. The carbon monoxide, an oxidizing gas that has a number of implications for Earth System functioning, on this occasion formed a plume that extended all the way across the Pacific Ocean to the west coast of North America. 


\section{Cascading impacts}

The nature of the Earth System's responses to the increasing anthropogenic forcing is more complex than simple cause-effect relationships, such as greenhouse gas emissions cause global warming. Fossil fuel combustion produces a range of gases that have a large number of cascading effects. For example, $\mathrm{CO}_{2}$ not only affects climate, but also directly affects how vegetation grows. It also changes the carbonate chemistry in the ocean, which in turn affects marine organisms.

Fossil fuel combustion also produces oxidizing gases such as nitric oxide and sulphur dioxide that have well-known effects such as acidification and eutrophication of ecosystems. However, these gases can eventually contribute to changes in fundamental Earth System functions such as the ability of the atmosphere to cleanse itself of pollutants. Aerosols produced by fossil fuel combustion can fertilise or reduce plant growth, depending on the circumstances, and directly affect human health. They also lead to large-scale direct or indirect modification of climate.

Land-cover and land-use change also trigger widespread cascading effects at local, regional and global scales. Box 3 (Pages 16-17) shows a few of the pathways by which initial local effects cascade through regional to global scales.

\section{Interacting processes and feedbacks}

Global change occurs for multiple reasons and from interacting forcing mechanisms. The responses of the Earth System are even more complex. Global change interacts with an almost bewildering array of natural variability modes and also with other human-driven effects at a number of scales (Box 4). Especially important are those cases where interacting stresses cause a threshold to be crossed and a step-change in functioning to occur.

Some of the most striking examples of interacting processes involve the interplay between land-use change and climate variability. In March/April 2001 a massive dust storm originating in northern China not only hit the major cities of eastern China but also travelled all the way across the Pacific Ocean and blanketed areas of western North America with a layer of dust. The origins of the dust storm are complex and not due to one single cause. A longterm drying trend in the climate of northwest China has been observed, and recent studies have linked this, at least partly, to the past land-use change that has converted much of East Asia's land-cover to agriculture. The situation is exacerbated by presentday land-use change, perhaps related to policy aimed at replacing agricultural land lost to urbanisation in the east to off-setting land-clearing for agriculture in the west. This newly cleared land is almost always in semi-arid regions and is marginal for agriculture. The current situation, in which especially severe dust storms have occurred over the last three years, is the result of a cascade of interacting factors over several centuries - a double-whammy of past and present land-use change coupled with short-term climate variability, longer term climate trends, and changes in human institutions and policy.

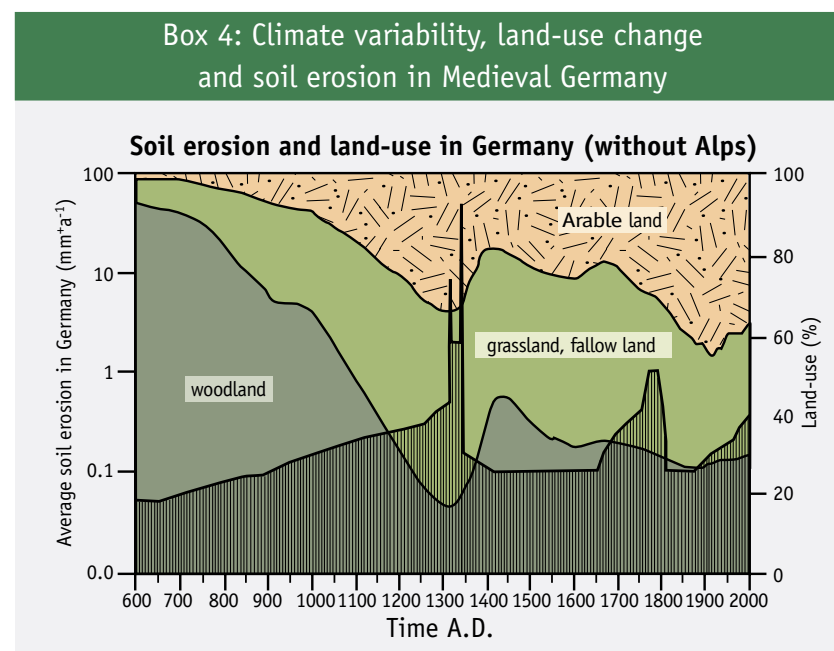

Massive soil erosion events in Germany in the early to mid 1300 s demonstrate the powerful nature of land use-climate variability interactions. For centuries from about $600 \mathrm{AD}$ the increasing population of Germany had steadily cleared forests and woodlands for agriculture; by the early $1300 \mathrm{~s}$ only $15 \%$ of the land remained forested. Changing land cover increased runoff by up to $60 \%$. When a rare (1000-year) rainfall event hit central Europe in 1342, the flow rates in rivers through Germany were enormous, exceeding maximum $20^{\text {th }}$ century flow rates by 50 to 200 times! The cascading impacts through the human/ environment system were profound and continued for over a century. Floods wiped out crops, villages and infrastructure such as bridges. Soil loss was extreme. Agricultural production subsequently dropped and famines ensued. A few years later the bubonic plague arrived in Germany; more than a third of the already weakened population died. For over 100 years, agricultural land was abandoned and the amount of forest and woodland increased by three times, again changing the rates of evapotranspiration, runoff and soil erosion. The situation finally stabilised again in the late $16^{\text {th }}$ century. Figure adapted from Bork et al. (1998) Landschaftsentwicklung in Mitteleuropa. Wirkungen des Menschen auf Landschaften, Gotha (KlettPerthes) by the PAGES (Past Global Changes) International Project Office. 


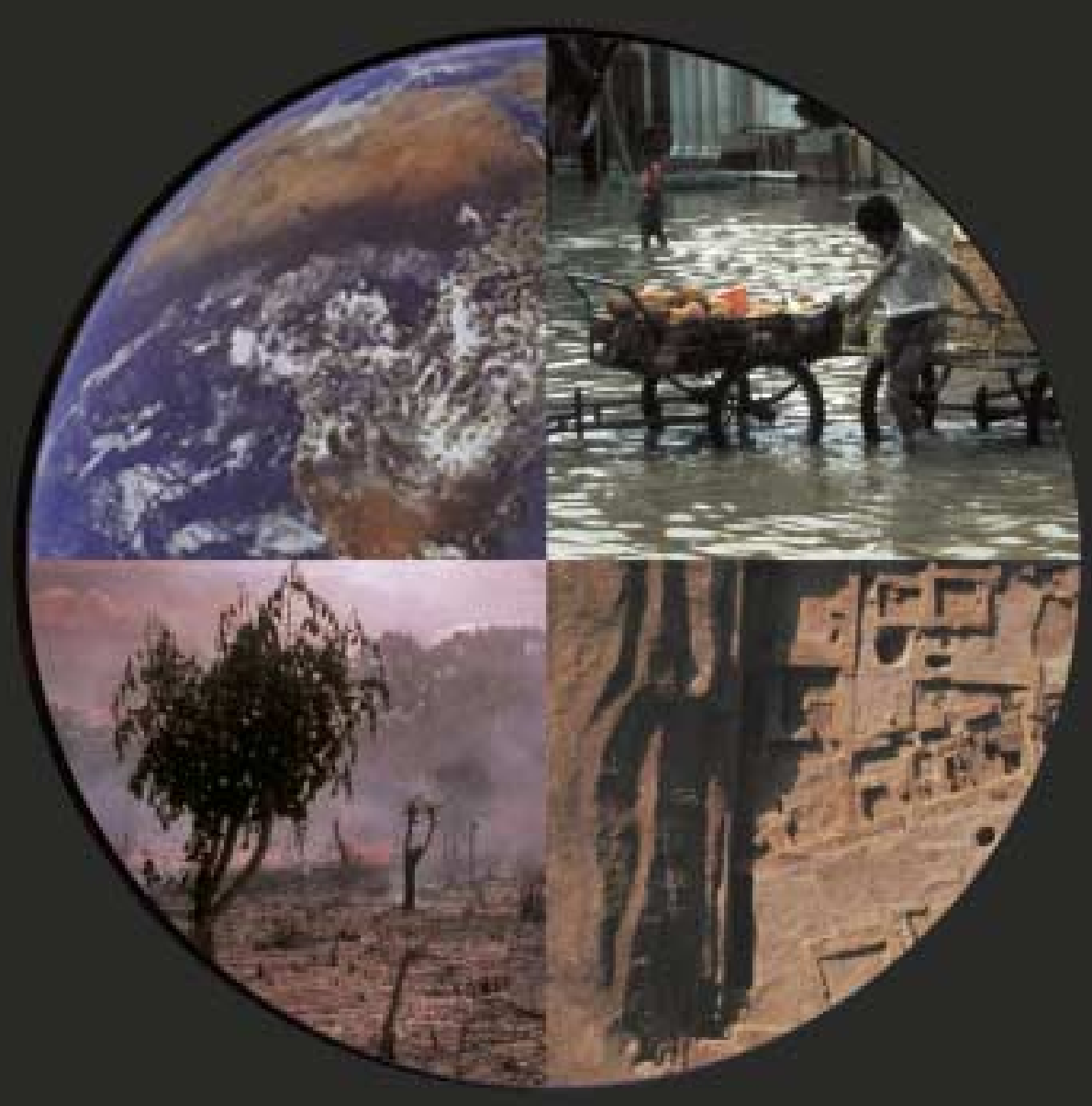

\section{Living with Global Change}

The changes that are occurring to the functioning of the Earth System have implications for human well-being. Basic goods and service supplied by the planetary life support system, such as sufficiency and quality of food, water resources, air quality, and an environment conducive to human health, are all being affected by global change. At another level, global change poses potentially serious consequences for the stability of the Earth System itself.

\section{Anticipating the consequences}

THERE IS NOW UNEQUIVOCAL evidence that human activities are affecting Earth's environment at the global scale. Increasingly strong evidence suggests that the functioning of the Earth System is changing in response. How might these apparently accelerating changes affect human well-being? Global change is now intersecting with the two major resource issues of the $21^{\text {st }}$ century - food and water. How can expanding human populations obtain adequate supplies of food and water in the face of accelerating changes to Earth System functioning, and without driving further change to the System in the process?
Studies of the past give clues as to how earlier civilisations were impacted by natural variability in the Earth System, and the consequences for their resource base. The success or failure of past civilisations is undoubtedly due to a variety of factors, especially to cultural and social organisation. However, in some cases there is convincing evidence that climate variability, especially in the hydrological cycle, was an important factor, perhaps even a decisive factor, in determining the fate of a particular civilisation (Fig. 9). At the very least, we know that human societies, including those of today, can be significantly affected by extreme events such as floods and droughts and can be seriously damaged by sequences of such events. 


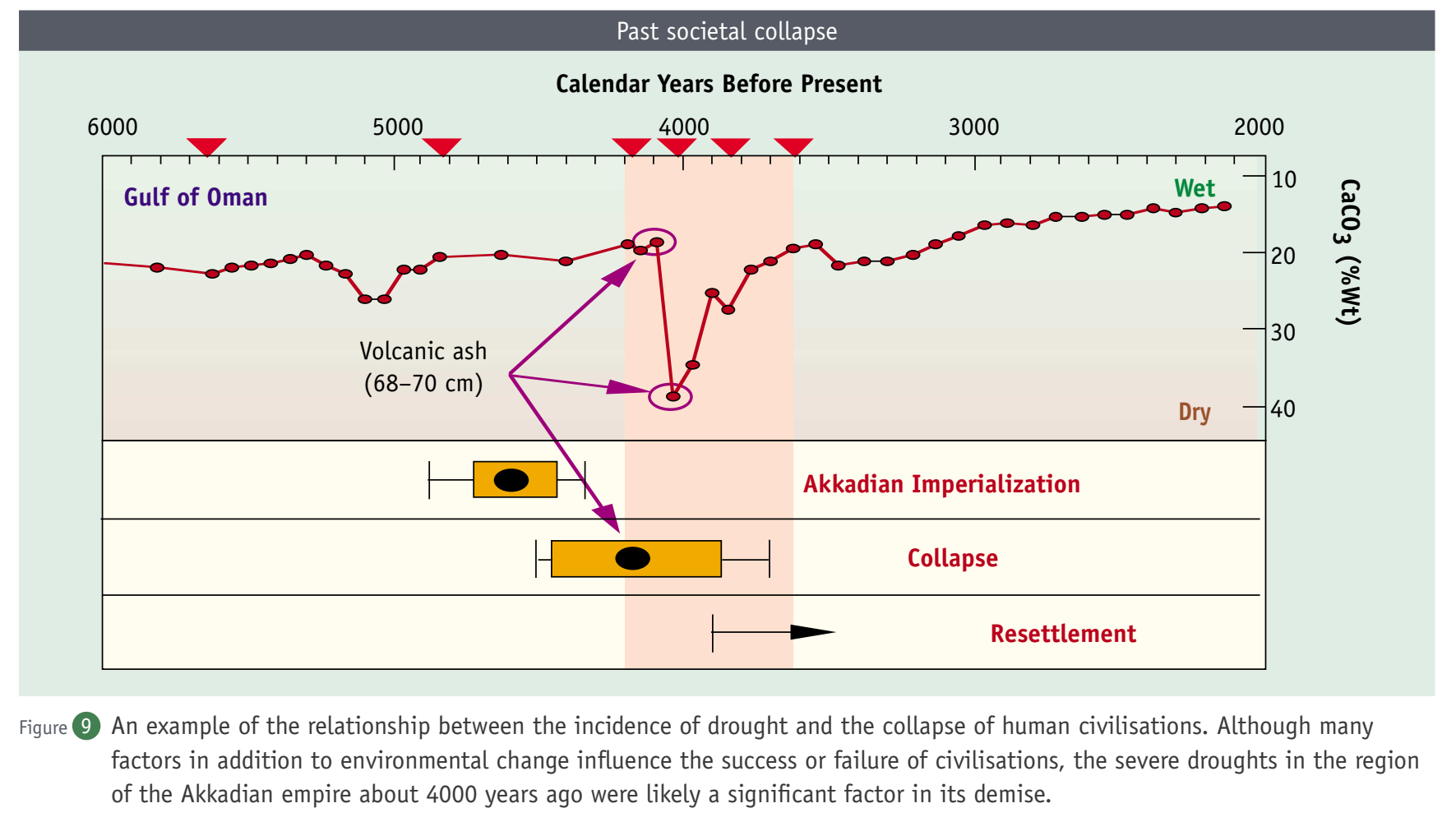

How can we anticipate the consequences of contemporary global change for human societies? The scenario-driven approach for impact studies is the most common, and has achieved considerable success. The approach is often to use a climate change scenario for 50 - 100 years to drive models of changes in the biophysical environment, for example, crop production. These impacts can then be further linked to simulate socio-economic consequences. More sophisticated approaches, such as integrated assessment techniques, allow both the interaction of a number of global change drivers and the feedbacks of impacts/consequences to the scenarios of change themselves. Despite their success, scenario-driven approaches suffer from a number of limitations, including propagation of uncertainties through model chains, problems in identifying and simulating threshold effects and nonlinearities, and difficulties in handling multiple, interacting stresses.

The classical scenario-driven approach has essentially been used to investigate the impact of a single stress, climate change for example, on particular sectors such as agriculture, human health and tourism. A proposed alternative approach, more realistic and more useful, starts by considering the outcomes of change that might be wanted or avoided for a particular societal group or ecosystem, for example, changes in food security or biodiversity.
The approach then investigates the critical thresholds and most important driving factors for change. This type of reverse vulnerability analysis allows the consideration of multiple and interacting stresses on the Earth System and the creation of rich and powerful scenarios of the System as a whole.

\section{Multiple, interacting effects}

In the past decade, the dominant focus of concern in global change research has been on single changes, especially climate change, despite the fact that many environmental changes that are global in extent or effect are underway concomitantly. At the local and regional scale, attention has often been focused on urban air pollution, toxic chemicals, acid rain, and other problems in isolation. In future, the focus will have to be on the interactions among agents and impacts of change at local, regional, and global scales.

Coral reefs, an important source of food for small island states and an economic resource for a large number of countries, illustrate well the nature of multiple, interacting stresses. Natural disturbances are an important part of coral reef dynamics. Even without any human stresses, reefs are subject to predation and grazing, storms and hurricanes, natural episodes of bleaching, crown-of-thorn outbreaks and natural epidemic diseases. In most cases, the 


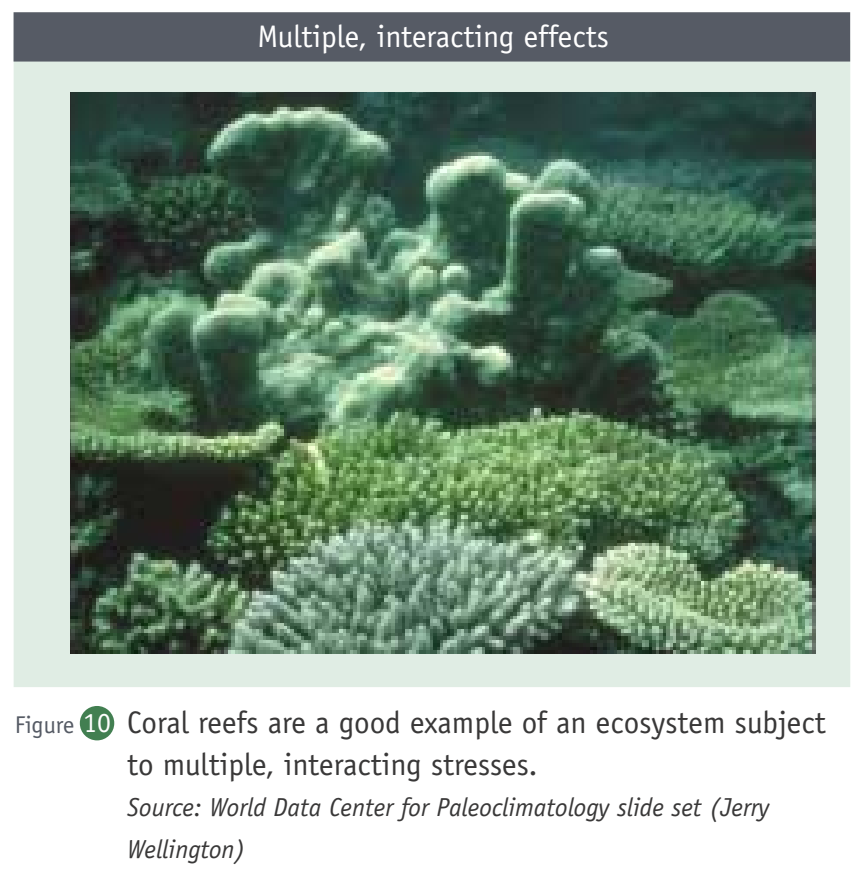

reefs cope with these disturbances and recover to maintain their structure and function within the same state.

Over the last decades or century, an increasing number of stresses of human origin have begun to interact with the natural disturbance dynamics of coral reefs. These include increasing nutrient loadings from on-shore agricultural and industrial activities, changing structure of reef ecosystems due to fishing and the pressures of rapidly growing tourism, especially the location of tourist facilities on the reefs themselves.

Global change is adding even more stresses. Increasing atmospheric $\mathrm{CO}_{2}$ leads to increased $\mathrm{CO}_{2}$ in the upper ocean layers, changing carbonate chemistry and thus the ability of reef organisms to create their calcium carbonate shells. A doubling of atmospheric $\mathrm{CO}_{2}$ is estimated to lead to a $30 \%$ reduction in calcification rate of reef organisms. Warming of the upper layers of the ocean will also affect reefs, as will any increase in storminess or hurricane frequency.

The fate of coral reefs will not be determined by global change itself acting in a simple cause-effect relationship. Instead, global change, interacting with the natural dynamics of the coral reef ecosystem and with other human-driven stresses, is likely to drive reef ecosystems into other states.

\section{Risks for the Earth System}

The palaeo-record shows that abrupt changes and surprises are a common feature of the Earth System, and that environmental extremes beyond those recorded during the period of instrumental record occur frequently. The stratospheric ozone episode (Box 5) demonstrates that catastrophic failures of the Earth System are not only possible, but that humankind narrowly escaped one very recently. Other catastrophic failures are possible as the Earth System as a whole adjusts to an ever-accelerating suite of interacting human forcings.

An example of a potentially catastrophic perturbation in the Earth System is a change in the capacity of the terrestrial and marine biospheres to slow the buildup of atmospheric $\mathrm{CO}_{2}$. It is possible that this ability might weaken or fail later this century. Currently land and ocean sinks remove, on average, over half of the $\mathrm{CO}_{2}$ emitted to the atmosphere by fossil fuel combustion. The land sink is highly sensitive to climate variability, with the sink strength reduced in warm years. Models based on the processes controlling terrestrial sinks suggest that the sink strength will level off around the middle of the century and could drop thereafter (Fig. 11). At the same time the build up of $\mathrm{CO}_{2}$ will continue inexorably unless effectively abated.

Ocean uptake of $\mathrm{CO}_{2}$ is also sensitive to temperature, as the solubility of $\mathrm{CO}_{2}$ in seawater decreases as the water warms. Simulations of the processes that control the biological uptake of

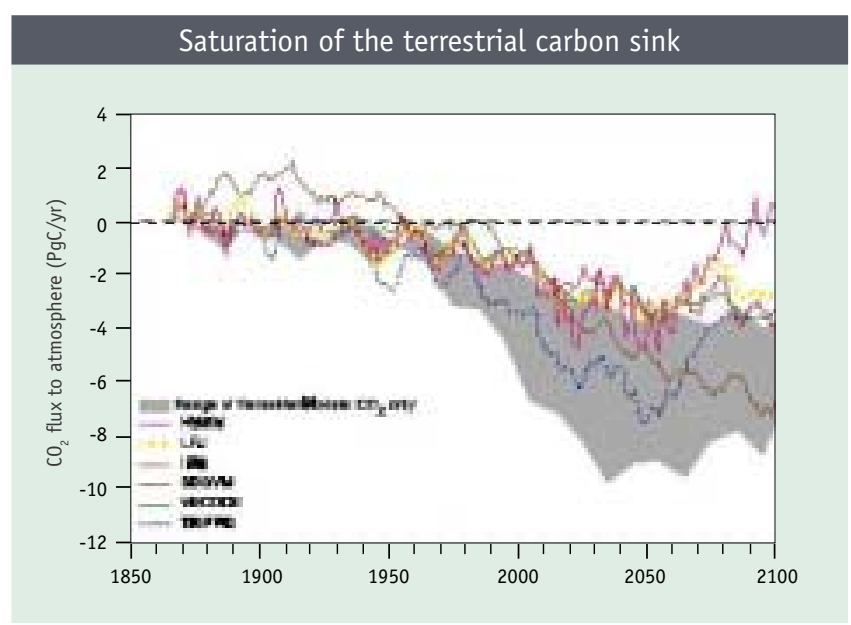

Figure 11 Model simulations of the ability of the terrestrial biosphere to absorb $\mathrm{CO}_{2}$ from the atmosphere as atmospheric $\mathrm{CO}_{2}$ concentration and climate change. Shaded area in grey represents results for changing $\mathrm{CO}_{2}$ concentration only. From the late 1800 s to 2050 the land surface acts as an increasing sink. After 2050, the models suggest that the terrestrial biosphere loses its capacity to absorb additional carbon from the atmosphere. The carbon 'sink' becomes saturated. Source: Cramer et al.(2001) Glob. Ch. Biol. 7, 357-374. 
$\mathrm{CO}_{2}$ in the oceans suggest that this sink, too, will weaken with projected climate change. With the major processes that sequester carbon from the atmosphere likely to weaken during this century, the Earth System brake on human-driven $\mathrm{CO}_{2}$ build-up in the atmosphere could fail and the concentration could surge strongly, leading to a chain of positive feedbacks in the Earth System that could propel it into another state.

\section{Box 5: Stratospheric ozone: A lucky escape}

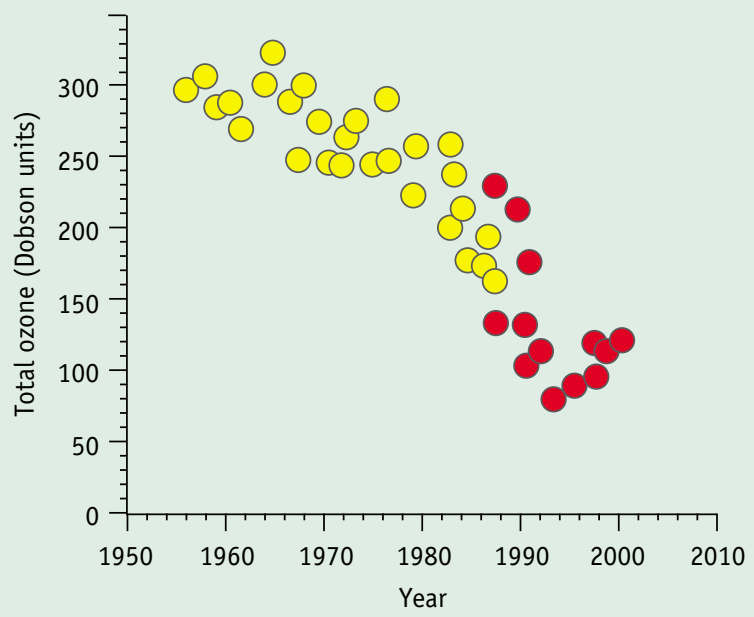

Source: British Antarctic Survey

The development of the ozone hole was an unforeseen and unintended consequence of widespread use of chloroflurohydrocarbons, as aerosols in spray cans, solvents, refrigerants and as foaming agents. Had, inadvertently, bromofluorocarbons been used instead, the result could have been catastrophic. In terms of function as a refrigerant or insulator, bromofluorocarbons are as effective as chlorofluorocarbons. However, on an atom-for-atom basis, bromine is about 100 times more effective at destroying ozone than is chlorine. As Nobel Laureate Paul Crutzen has written "This brings up the nightmarish thought that if the chemical industry had developed organobromine compounds instead of the CFCs - or, alternatively, if chlorine chemistry would have run more like that of bromine - then without any preparedness, we would have been faced with a catastrophic ozone hole everywhere and at all seasons during the 1970s, probably before the atmospheric chemists had developed the necessary knowledge to identify the problem and the appropriate techniques for the necessary critical measurements. Noting that nobody had given any thought to the atmospheric consequences of the release of $\mathrm{Cl}$ or $\mathrm{Br}$ before 1974, I can only conclude that mankind has been extremely lucky."

(Source: P. Crutzen (1995) My life with $\mathrm{O}_{3^{\prime}}$ NOX and other YZOxs. Les Prix Nobel (The Nobel Prizes) 1995. Stockholm: Almqvist \& Wiksell International. pp. 123-157).
Another potential catastrophic perturbation in the Earth System is the slowing or shutting-down of the North Atlantic thermohaline circulation and an accompanying shift in the Gulf Stream. A great deal of heat is transported globally with the movement of ocean water. The eastern North Atlantic region, for example, is a recipient of heat in this process that makes human existence at $60^{\circ} \mathrm{N}$ a much more pleasant experience in Scandinavia than it is in northern Canada or Siberia. The circulation that delivers heat to the North Atlantic is driven by the formation of ice in the Greenland and Arctic Seas. Salt is forced out of the ice as it forms. Thus, the water around the ice is both cold and saline. The increased density causes the surface water to sink. As it does, warmer waters from the Gulf Stream and North Atlantic Current replace it and complete the circulation. As the warmer waters cool, they release their heat to the adjacent regions. Were the circulation to weaken or reverse, the effect on climates would be pronounced. Such abrupt shifts are known to have occurred naturally in the past.

The palaeo-record show strikingly abrupt climate changes in the past 15,000 years in the Northern Hemisphere; there is increasing evidence that these changes were associated with a slowdown or reorganisation of oceanic circulation in the North Atlantic. Can the current combined human forcings of the Earth System trigger a similar change in the coming decades? As yet, the question cannot be answered. It must, however, be answered in future if the possibility of a major catastrophe is to be avoided. 


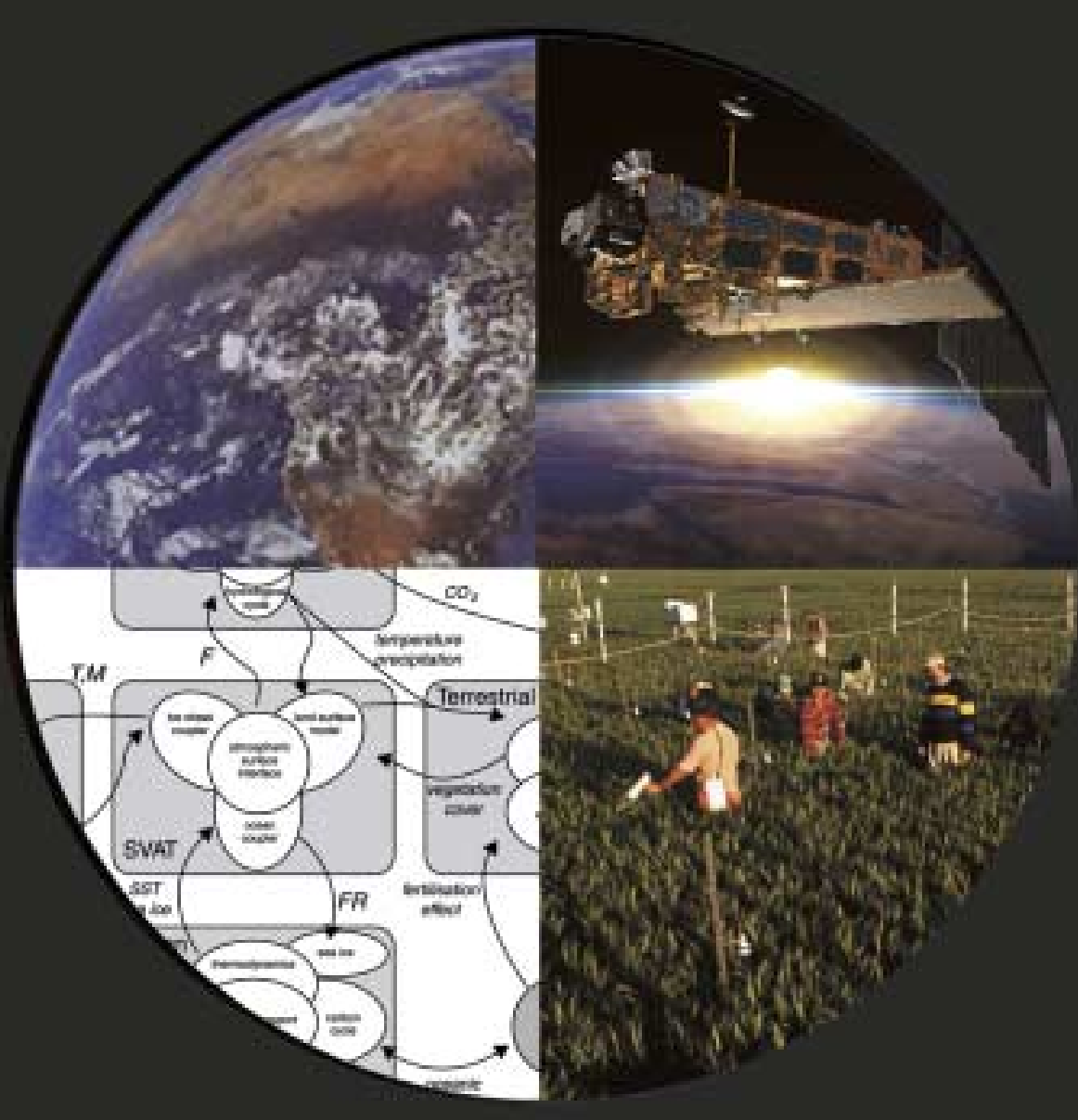

\section{Making Earth System Science}

The challenge of understanding a changing Earth demands not only systems science but also a new system of science. This new approach must retain and strengthen existing tools for studying the planetary machinery, develop new systems-level approaches for integration and build an effective framework for substantive collaboration between the social and natural sciences.

\section{The dawn of a new era}

THE UNPRECEDENTED CHALLenges of a rapidly changing Earth demand unprecedented strategies to generate new scientific knowledge to support societal action. Much exciting new knowledge, insights and understanding are flowing from disciplinary research on parts of the Earth System. Even more is needed. However, the biggest challenge is to develop a substantive science of integration, putting the pieces together in innovative and incisive ways towards the goal of understanding the dynamics of the planetary life support system as a whole.

The research required to address the futureoriented research agenda of Earth System science must have new characteristics. It must:

- continue to support and facilitate the study of pieces of the planetary machinery in fine detail, but from a systems perspective,

- embed the insights of this classical analytical science - the identification of cause-effect relationships - into complex systems analysis which directly address the synergies, interactions and nonlinearities that defy the traditional approach on its own,

- complement the bottom-up approach to integration with the development of explicit systemslevel research strategies, addressing directly the phenomena which emerge at larger scales in complex systems, and

- above all, it must transcend disciplinary boundaries across the natural and social sciences, as Earth System science is ultimately concerned 
Analytic Questions:

What are the critical thresholds, bottlenecks and switches in the Earth System? What are the major dynamical patterns, teleconnections and feedback loops?

What are the characteristic regimes and timescales of Earth's natural variability?

What are the anthropogenic disturbance regimes that matter at the Earth System level, and how do they interact with abrupt and extreme events?

Which are the most vulnerable regions under global change?

Methodological Questions:

What are the principles for constructing representations of the Earth System that aggregate unnecessary details and retain important system-level features? What levels of complexity and resolution are required?

What is the optimal global strategy for generating, processing and integrating relevant Earth System data sets?

What are the best techniques for analyzing and possibly predicting irregular events?

What are the most appropriate methodologies for integrating natural science and social science paradigms, research approaches, and knowledge?
Normative Questions:

What are the general criteria and principles for distinguishing nonsustainable and sustainable futures?

What are the human carrying capacities of Earth under various assumptions and values? What processes, both human and natural, are most likely to constrain or compromise these goals?

What are the potential changes in state of the Earth System that can be triggered by human activities but should be avoided?

What are the equity principles that should govern global environmental response strategies?

Strategic Questions:

What is the optimal mix of adaptation and mitigation measures to respond to global change?

What is the best distribution of nature reserves and managed areas on the planetary surface?

What are the knowledge levels, value/culture bases, options and caveats for technological fixes like geoengineering and genetic modification?

What is the structure of an effective and efficient system of global environment and development institutions?

Sample research questions under development to help guide Earth System science in the future.

Source: GAIM (Global Analysis, Integration and Modelling) Task Force of the IGBP.

with issues that lie well beyond any single field of study,

An integrative Earth System science is already beginning to unfold. Observations of Earth from the surface and from space are yielding new insights almost daily, interdisciplinary research centres focused on global change are springing up around the world, and the global environmental change programmes are beginning to build an international science framework. What questions should guide this science? What new research strategies are required to deal with the complex nature of the Earth System? What tools are needed to do the work?

\section{Questions at the frontier}

The past decade of global change research has provided answers to many important questions, but in the process has generated new questions. Even more importantly, a level of understanding has now been achieved that allows the identification of key questions that can help set the agenda for systemslevel research on Earth's environment and that must be addresses on the road to global sustainability. Table 2 gives examples of the types of questions currently under development, ranging from analytical and methodological research questions to normative and strategic questions that rely on value-based judgments.

\section{Coping with complexity and irregularity}

Most environmental systems are characterized by a multitude of nonlinear internal interactions and external forcings. As a consequence, they do not often behave regularly and predictably, but rather exhibit chaotic dynamics or abrupt transitions to new modes of operation under appropriate forcing. These systems usually become even more complicated when human activities are involved, which introduces a further element of indeterminacy. All these generic difficulties are reflected and severely amplified at the Earth System level, where the connections and feedbacks of millions of entangled local, regional and global processes have to be considered.Typical examples of Earth System complexity and irregularity are the intricate patterns in space and time of carbon fluxes between the Earth's surface and the atmosphere, and the very abrupt and seemingly erratic temperature oscillations documented in the Greenland ice-core records. Nature-society interactions also tend to come in complicated functional patterns that defy the power of standard scientific analysis.

In order to cope with these challenges, Earth 
System science can take advantage of the considerable progress recently made in fields outside the usual arena of global change research - like nonlinear dynamics, complex systems analysis, statistical physics, scientific computing or artificial intelligence research. By combining, for example, arguments from bifurcation theory and stochastic analysis, the wild temperature fluctuations during the last ice age can be explained in large measure. There are now methods developed in biophysics that try to anticipate when critical systems thresholds will be crossed by detecting warning signs of the imminent phase transition. The latter approach is particularly relevant to Earth System analysis that attempts to identify the switch and choke points in the planetary machinery that might be inadvertently activated by human activities. In fact, science can even benefit from the existence of strong nonlinearities in the Earth System by devising an inverse sustainability strategy that calculates the critical anthropogenic perturbations to be avoided at all costs.

There are also novel ways to overcome some of the problems caused by uncertainties in data sets, process descriptions and simulation techniques instrumental to Earth System research. Certain techniques can be used, in particular, to construct weakly predictive models of complex nature-society patterns like degradation syndromes. An entirely new avenue towards integrated assessment of global change problems is the incorporation of large groups of real and proxy decision-makers into the very simulation process.

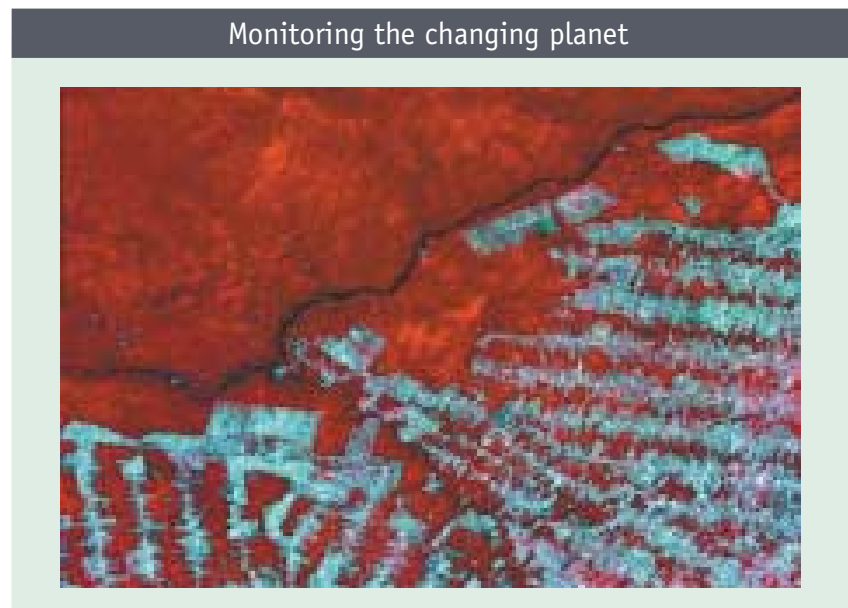

Figure 12 Observation from space of critical global change phenomena, such as land-cover change, is an essential component of Earth System science. The example here shows land-cover change in the Amazon Basin, Brazil. Tropical forest appears bright red, while pale red and brown areas represent cleared land.

Source: National Aeronautics and Space Administration (NASA), USA.

\section{The Earth System toolkit}

Making Earth System science happen demands an extensive toolkit comprised of existing and developing techniques, such as fully coupled threedimensional atmosphere-ocean general circulation models, and novel methods and approaches like those described above. The challenge is to deploy the toolkit not as a series of independent instruments that examine parts of the planetary machinery in isolation, but as an interlinked suite of probes and processors that sense and interpret Earth System behaviour in a holistic way.

Palaeo-science. The only way to investigate Earth System processes that operate on timescales longer than the period of contemporary instrumental records is through palaeo-environmental research. The Earth System leaves traces of and clues to its behaviour in a wide variety of archives - marine and lake sediments, ice caps, tree rings, long-lived corals and archeological remains and other historical records. Although palaeo-science has achieved remarkable success in shaping the present understanding of Earth System dynamics, significant challenges remain in building a more integrative global system of palaeo-observation and in recovering key archives of past change before they disappear in the current era of accelerating change.

Contemporary observation and monitoring. Observation of the Earth from space has revolutionised human perspectives and understanding of the planet, and the expanding array of sophisticated remote sensors promises a flood of valuable data, complementing observations on the Earth's surface (Fig. 12). Creative approaches for documenting the role of people in the Earth System can illuminate the human dimensions of planetary dynamics. Well-conceived and -deployed global monitoring networks can provide powerful early warning systems for global environmental change. Sets of observations organised into an Earth System Atlas can help to visualise and quantify the extent and rate of global change.

Place-based case studies. Tools are required to address directly the question of multiple, interacting stresses at a particular place with its unique set of characteristics. Existing and developing methods range from integrated regional-scale studies of global change to vulnerability analysis, identification of hot spots of risk and identification and simulation of syndromes of environmental degradation. Reconstruction of global dynamics from regional 
patterns is yet another technique in the Earth System toolkit.

Planetary patterns emerge more clearly when small-scale or site-specific measurements and process studies are carried out in a consistent and comparative way across the globe. Scientific networks tackling aspects of the Earth System form the backbone of the emerging research framework (Fig. 13). Major challenges of site representivity and stratification, scaling up and aggregation, and interpolation and interpretation stand between the individual studies and their application to Earth System questions.

Simulating Earth System dynamics. A vast array of mathematical models has been designed to simulate the Earth System or parts of it. Simple, stylized Earth System models focus on description and understanding of the major features of the planetary machinery while comprehensive Earth System simulators are being assembled from the most sophisticated component modules. In between, Earth System models of intermediate complexity have already proven to be effective tools for both hindcasting and forecasting Earth System behaviour (Fig. 14).

Experimental simulation of future environmental conditions on Earth provides the means to study the structure and functioning of ecosystems under new combinations of atmosphere and climate. Addition and removal of species provide insights into the

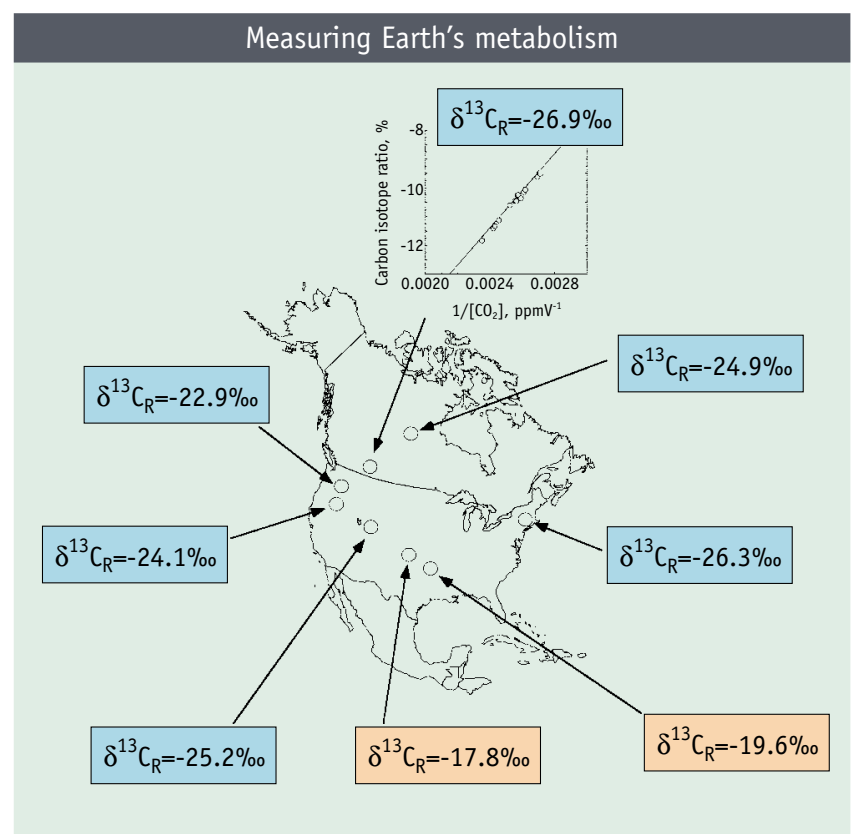

Figure 13 International networks are fundamental tools in Earth System science. The North American component of a global consortium of studies using isotope techniques to understand basic ecosystem processes and their role in the exchange of trace gases with the atmosphere. Source: Diane Pataki and GCTE (Global Change and Terrestrial Ecosystems) International Project Office.

responses of biological systems as their complexity changes. Manipulation of element flows, such as the addition of iron to nutrient-poor areas of the oceans, mimics system responses to changes in biogeochemical cycling.

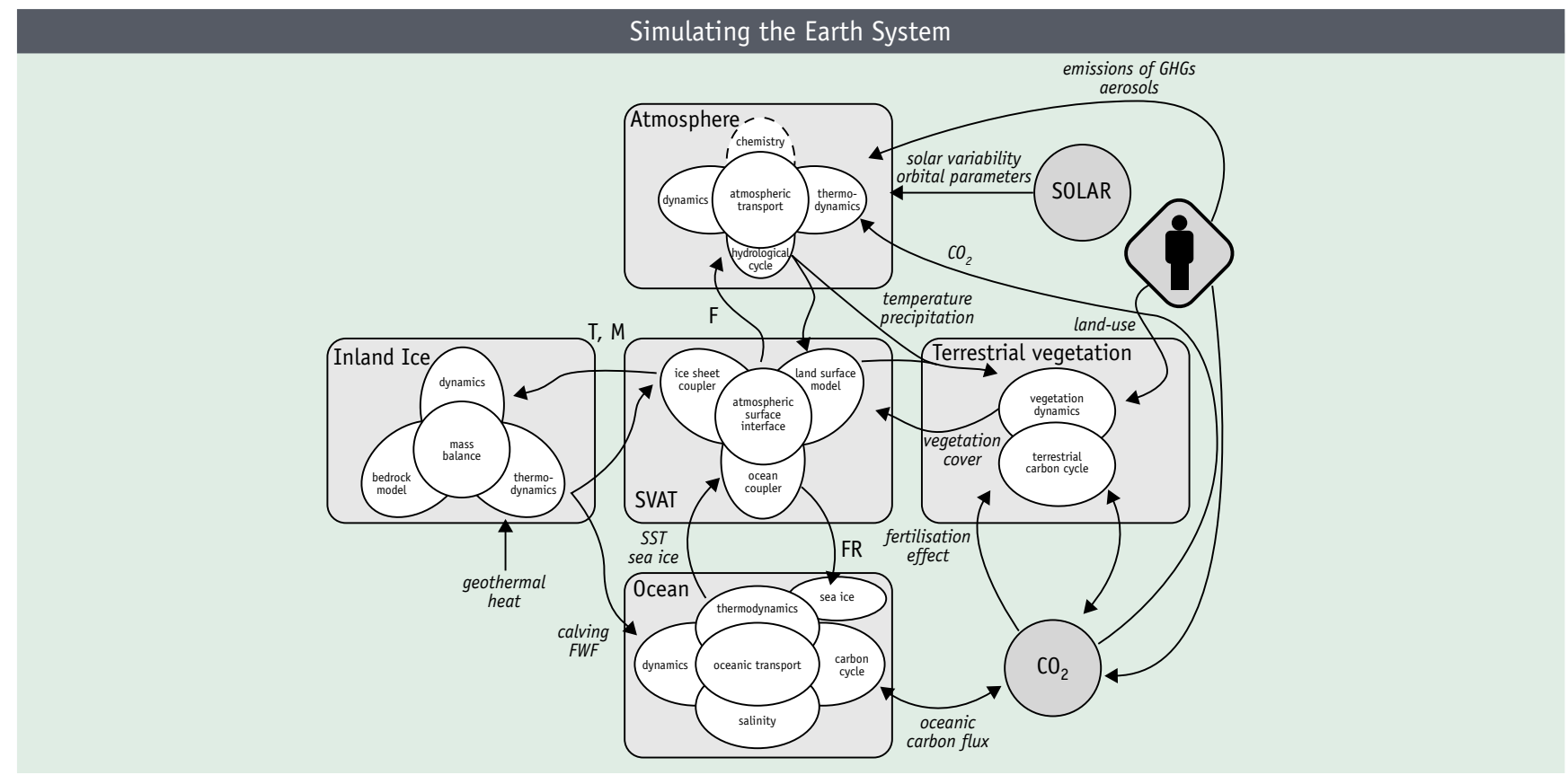

Figure 14 The structure of the CLIMBER model, an example of an Earth System model of intermediate complexity.

Source: Petoukhov et al. (2000) Clim. Dyn. 16, 1-17. 


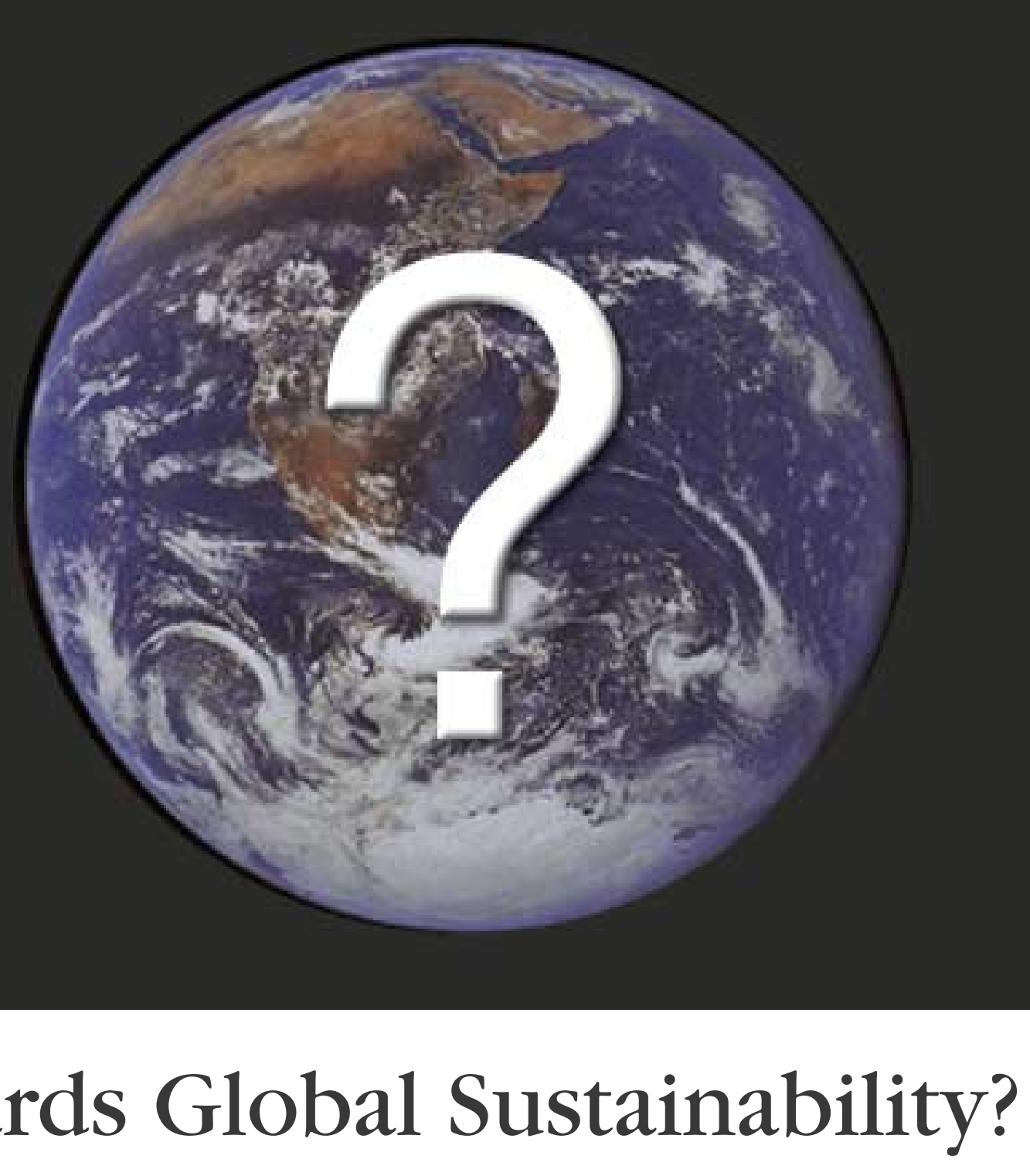

\title{
Towards Global Sustainability?
}

\author{
Human-driven changes are pushing the Earth System beyond its \\ natural operating domain into planetary terra incognita. Management \\ strategies for global sustainability are urgently required. Earth System \\ science is the key to implementing any approach towards good \\ planetary management, as it can provide critical insights into the \\ feasibility, risks, trade-offs and timeliness of any proposed strategy.
}

\section{Good management of the Earth System}

Humanity is already managing the planet, but in an unconnected and haphazard way driven ultimately by individual and group needs and desires. As a result of the innumerable human activities that perturb and transform the global environment, the Earth System is being pushed beyond its natural operating domain (Fig. 15). This excursion into planetary terra incognita is accelerating as the consumption-based Western way of life becomes more widely adopted by a rapidly growing world population. The management challenges to achieve a sustainable future are unprecedented.

As a business-as-usual approach to the future could trigger abrupt changes with potentially catastrophic consequences, alternative strategies of planetary management are clearly needed. These could range from reactive strategies that try to avoid the worst environmental changes now under way to more proactive ones that define and realise environmental quality and safety goals acceptable to the overwhelming majority of humankind.

Once a management strategy has been chosen, it will have to be implemented. The options to do this include the use of educational campaigns to transform life-styles, a wide range of economic incentives and instruments to encourage shifts in behaviour, and highly controversial high-technology geoengineering.

Earth System science is the key to implementing 
any approach towards good planetary management, as it offers critical insights into the feasibility, risks, trade-offs and timeliness of any strategy considered. Integrated Earth System models, for example, allow many different scenarios of interacting natural and human-driven changes to be developed and evaluated. Such models and the scenario development that follows from them must evolve further through integrated interdisciplinary research, and in continuing dialogues between the scientific community and policymakers at a variety of levels.

\section{Advancing sectoral wisdom}

In 1987 the Bruntland Commission's Our Common Future detailed the challenges to the environment and sustainability arising from activities within particular sectors: energy, industry, agriculture, urban systems, living resources and human population. In the years since the Bruntland report, substantial progress has been made, yet much, much more is necessary. In industry, for example, there have been considerable improvements in reducing and reusing materials and reducing wastes. This trend towards dematerialisation must be accomplished universally and at much greater rates. In the energy sector, gradual progress has been made in increasing efficiency and in development of alternatives to fossil fuel sources, but critical air pollution and global greenhouse gas problems resulting from fossil fuel combustion continue to grow around the world. Dramatic increases in energy efficiency, decarbonisation and the development and utilisation of new sustainable energy technologies are needed.

In agriculture, continued increases in food production, and improvements in distribution and access, are needed urgently as the world's human population continues to grow and dietary preferences change. The challenge of increasing agricultural production is substantial and much evidence suggests that the gains of the past decades will be difficult to repeat in the next decades. These and other sectoral challenges are as significant today as they were in 1987.

While the importance of individual sectors has not diminished, it has become clear that sectoral interaction and interdependency is increasing. The consequences are cumulative, sometimes nonlinear, and may be associated with abrupt changes and the crossing of critical thresholds. Some of the world's most critical resources - water, air, and ecosystems
- are at risk because of the connectivity of sectoral activities. Water resources, for example, reflect the demands and activities of all sectors. Strategies for management of water are increasingly attempting to take integrative, regional approaches. Likewise, management of air quality recognises increasingly the multi-sectoral and regional, rather than local, determinants of air quality. In terms of sustaining ecosystem goods and services, the importance of overlapping sectoral activities has led to the development of more integrated landscape planning that reconciles ecosystem processes with human social and economic activities.

\section{Global science for global sustainability}

Sectoral science produced at local, landscape and regional scales provides a strong foundation for sustainability science. It is, however, not sufficient on its own. The urgent challenges of a changing Earth require, in addition, a global system of global systems science. A minimum of research design and infrastructure is needed to create an effective global system. The present international global environmental change programmes represent a first

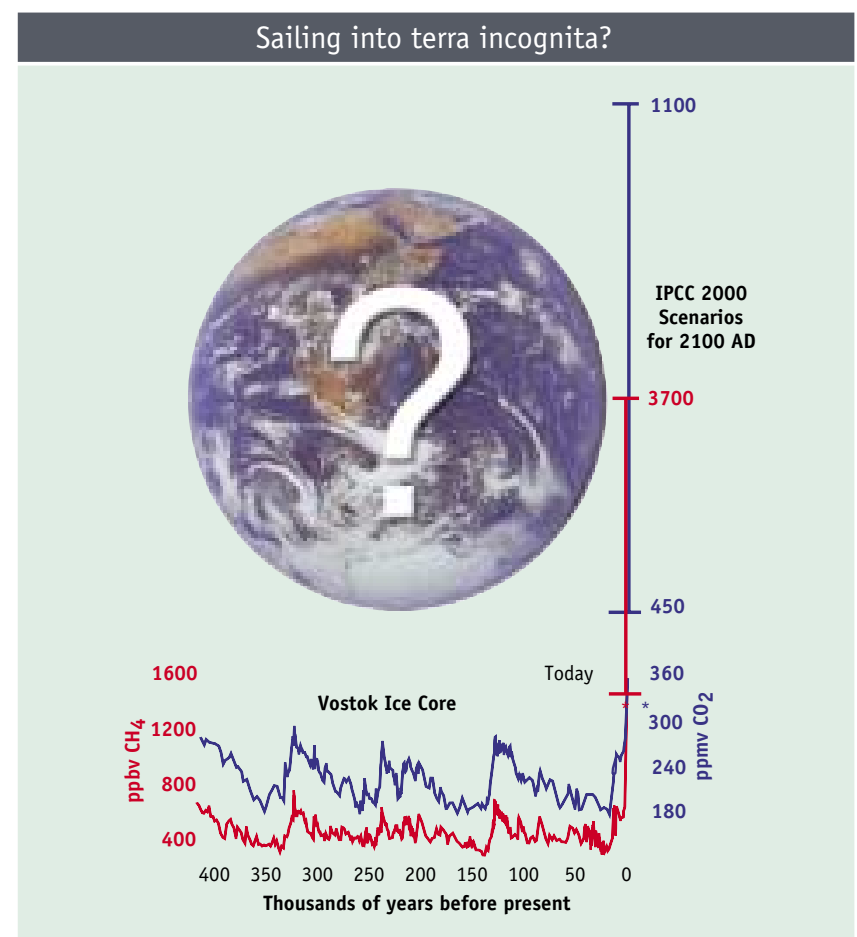

Figure 15 Atmospheric concentrations of the greenhouse gases $\mathrm{CO}_{2}$ and $\mathrm{CH}_{4}$ over the last four glacial-interglacial cycles from the Vostok ice core record. The present-day values and estimates for the year 2100 are also shown.

Adapted from Petit et al. (1999) Nature 399, 429-436 and the IPCC (Intergovernmental Panel on Climate Change) Third Assessment Report by the PAGES (Past Global Changes) International Project office. 


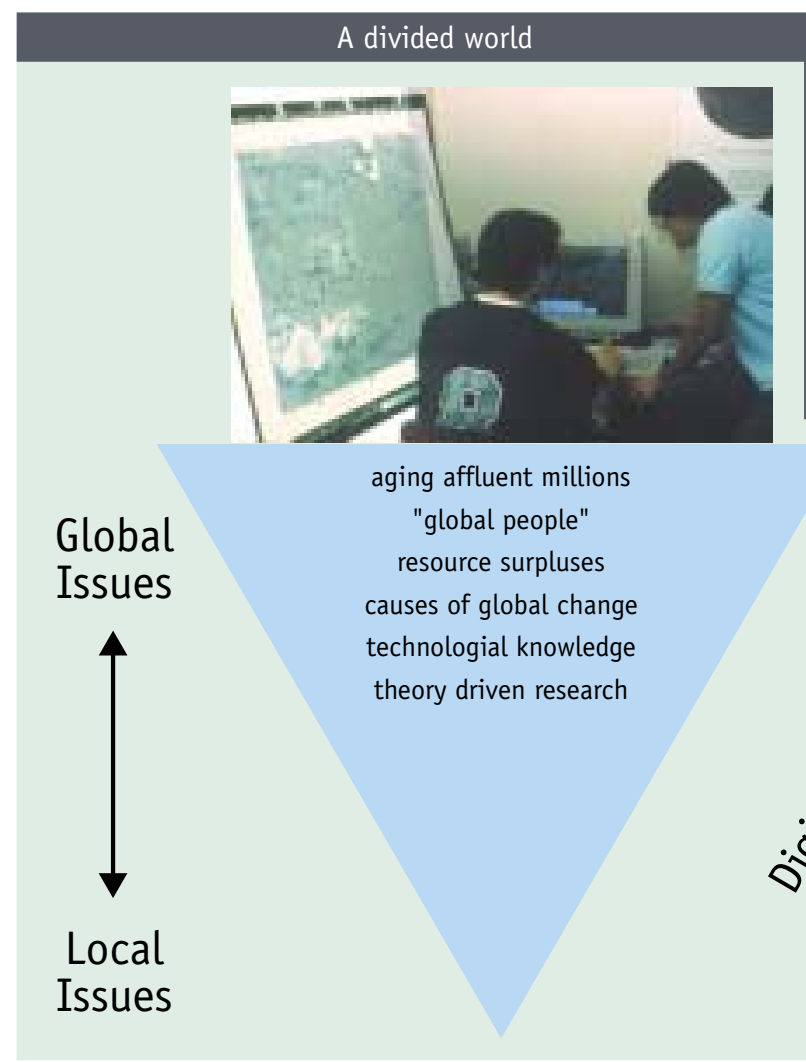

step towards such a global system, but they are subject to the vagaries of uncorrelated and insecure sources of funding and must rely on voluntary contributions of research from the scientific community. On the other hand traditional branches of so-called big science, like particle physics or space exploration, enjoy continued international support through well-funded mega-projects like CERN (Centre Europeén de Recherche Nucleáire) or the International Space Station. Ironically, the science instrumental for the preservation of the global life support system does not.

The transition to sustainability will be neither simple nor cheap. Adequate structures will be needed, in particular, to organise the international co-production of relevant knowledge through continuing dialogues between research and stakeholder communities. For making decisions under a wide range of uncertainties, a common knowledge base of clear, concise and unbiased scientific information must be available to politicians, business people, environmentalists and the general public to ensure informed debates on the nature of the problems and potential response options. A good example of a mechanism to produce such a knowledge base is the IPCC (Intergovernmental Panel on Climate Chenge) assessment enterprise, where the entire community of climate-change experts meets government representatives from around the world to convert the appropriate scientific literature into policy-relevant wisdom. This process may serve as model for creating a culture of scientific assessment that goes beyond the effects of climate change to encompasses the effects of global change in its entirety and all areas of endeavour important for Earth System management.

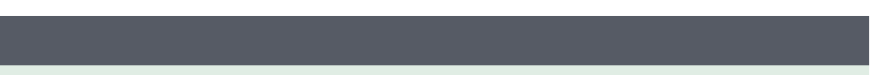

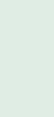

poor, young billions poverty "local people" resource shortages impacts of global change traditional knowledge

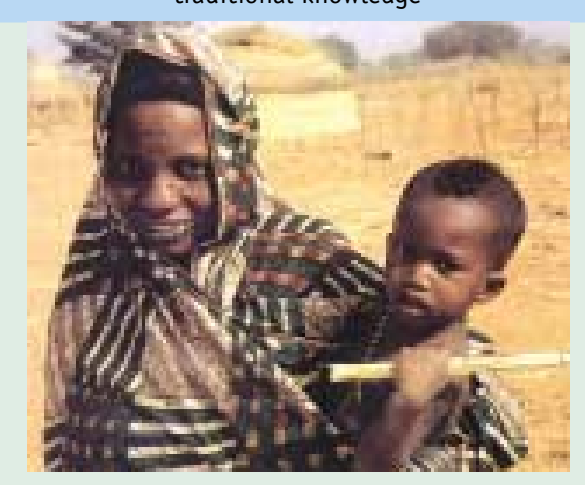

Figure 16 The challenge to achieve a sustainable future in the context of a divided world. The socio-economic, environmental and knowledge dichotomies are exacerbated by the deepening digital divide. Adapted from Kates et al. (2001) Science 292, 641-642.

Any global system of sustainability science will fail, however, if it does not stimulate and achieve the active participation of the developing world, i.e., of those regions where the capacity to undertake sustainability science is the weakest but where the impacts of global change will unfold in the most dramatic ways. Without this participation, the systems-order problems of the planet cannot be solved, let alone be identified. The challenge of achieving a truly global system of science is substantial; the challenge of bridging the divide between developed and developing countries across a broader range of human endeavours is much more daunting (Fig. 16). Both challenges must be met to achieve a sustainable future for planet Earth. 


\section{Challenges of a changing Earth}

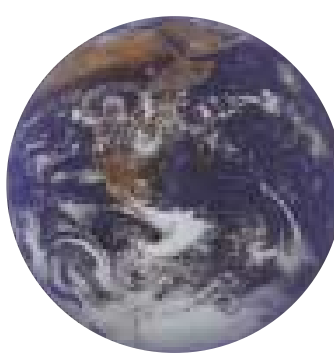

Much exciting science has been carried out and much has been achieved in more than a decade of global change science. Much remains to be done. The past decade of research, summarised in this booklet, has unveiled more and more about the complex and interrelated nature of the Earth System, and about the ways in which human activities are impacting the System. The research has clearly shown that the Earth System has moved well outside the range of natural variability exhibited over the last half million years at least.The nature of changes now occurring simultaneously in the global environment, their magnitudes and rates, are unprecedented in human history and probably in the history of the planet. The Earth is now operating in a no-analogue state.

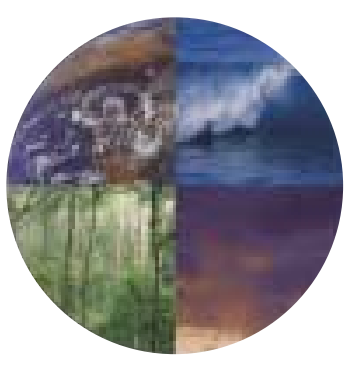

Although science has vastly improved our understanding of the nature of global change, it is much more difficult to discern the implications of the changes. They are cascading through the Earth's environment in ways that are difficult to understand and often impossible to predict. Surprises abound.The human-driven changes to the global environment will, at least, require societies to develop a multitude of creative responses and adaptation strategies. At worst, they may drive the Earth itself into a different state that may be much less hospitable to humans and other forms of life.

As global environmental change assumes a more central place in human affairs, science must accept the responsibility of developing and communicating the essential knowledge base that societies can use to debate, consider and ultimately decide on how to respond to global change. Ultimately, upon this science the preservation of the global support system for life on Earth depends. The challenge of ensuring a sustainable future is daunting. It can be met, but only with a new and even more vigorous approach to studying and managing an integrated Earth System.
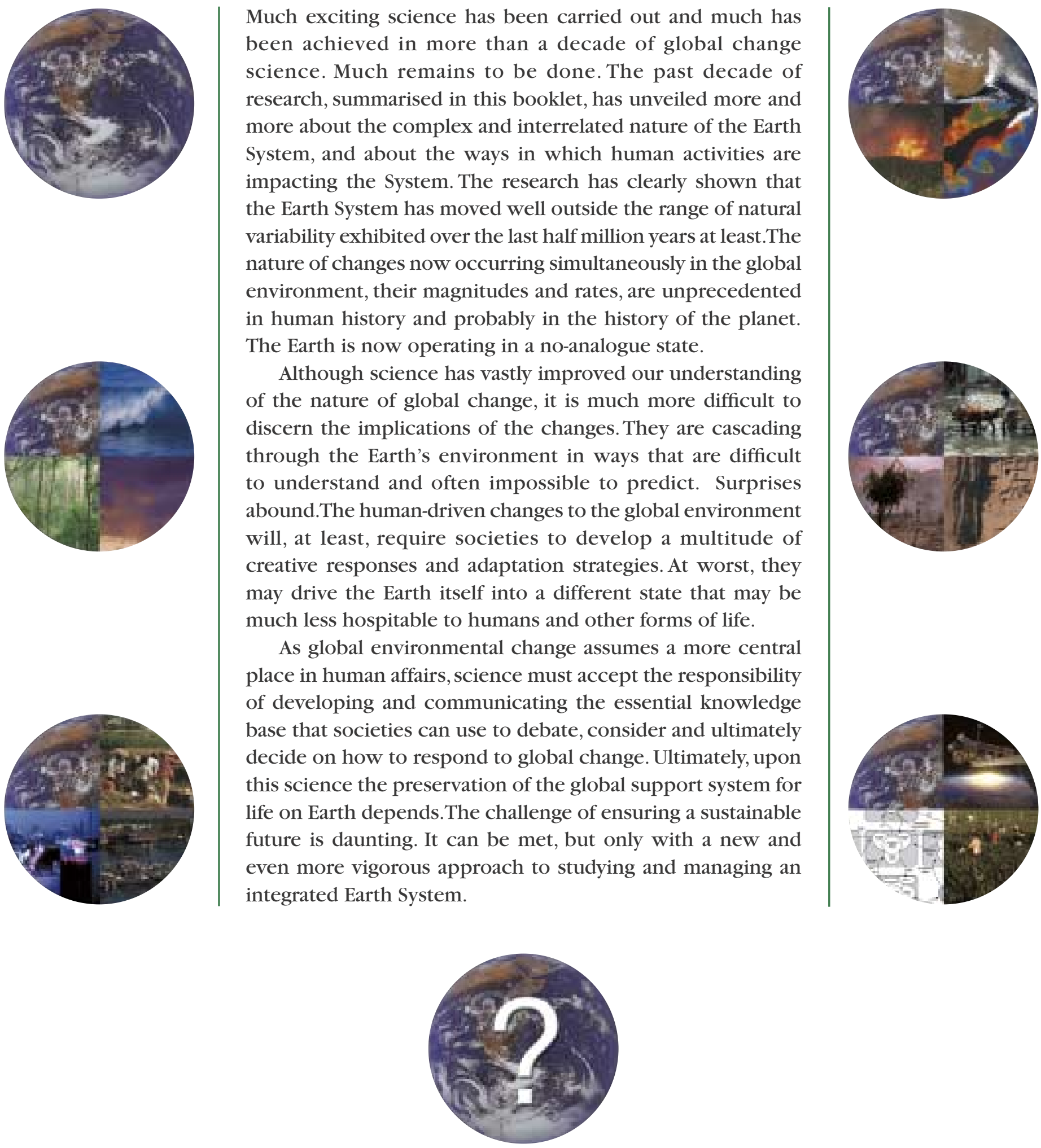


\section{About the Global Environmental Change Programmes}

\section{Objectives}

The International Council for Science (ICSU) is the common scientific sponsor of four international global environmental change programmes. These are the International Geosphere-Biosphere Programme (IGBP), the International Human Dimensions Programme on Global Environmental Change (IHDP), the World Climate Research Programme (WCRP) and DIVERSITAS. The common mission of these international scientific research programmes is to deliver scientific knowledge to help human societies develop in harmony with Earth's environment.

Each of the programmes pursues complementary aspects of the overall mission by working towards more specific scientific objectives:

IGBP: to describe and understand the interactive physical, chemical and biological processes that regulate the total Earth System, the unique environment that it provides for life, the changes that are occurring in this system, and the manner in which they are influenced by human actions.

IHDP: to promote and coordinate research aimed at describing, analysing and understanding the human dimensions of global environmental change, focussing on the causes and consequences of people's individual and collective actions.

WCRP: to determine the extent to which climate can be predicted and the extent of man's influence on climate through a quantitative understanding of the physical climate system.

DIVERSITAS: to unify the various approaches to the study of biodiversity, from the role of biodiversity in ecosystem functioning to the socioeconomic aspects, into a coherent international framework.

\section{Implementation Strategies}

The global environmental change programmes are built on interdisciplinarity, networking and integration. They address scientific questions where an international approach is the best or the only way to provide an answer. Built around the voluntary contributions of thousands of scientists working on all continents and in all ocean basins of the planet, the programmes add value to this large number of research projects through integrating activities aimed at achieving enhanced scientific understanding

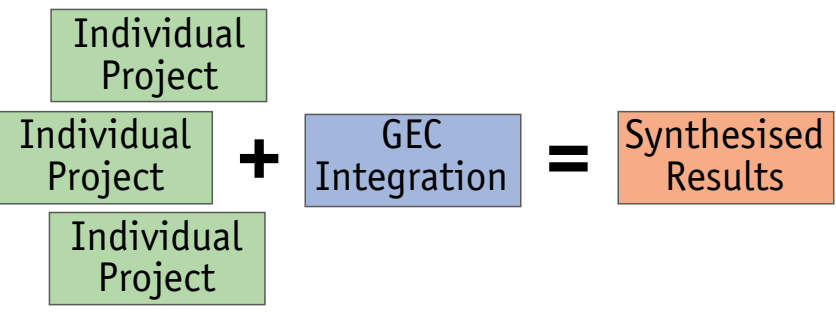

The integrating activities include:

- development of common international frameworks for collaborative research based on agreed agendas;

- Formation of research networks to tackled focused scientific questions;

- Promotion of standardised methodologies;

- Guidance of global database production;

- Undertaking model intercomparisons and comparisons with data;

- Facilitation of efficient strategies of resource allocation

\section{Joint Projects}

Earth System science provides the essential scientific base on which to build towards global sustainability. To contribute more directly to global sustainability issues, three of the global environmental change programmes, IGBP, IHDP and WCRP, are launching a small number of joint projects on key sustainability issues. DIVERSITAS will be invited to join the sponsoring group in the near future as appropriate.

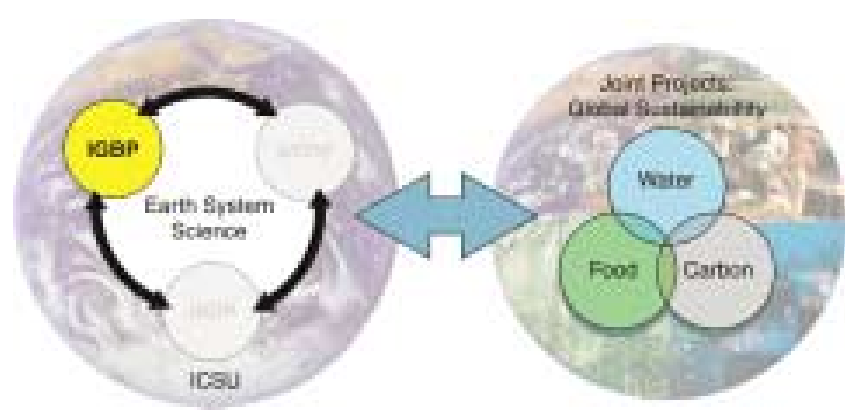

At present joint projects on the global carbon cycle, food systems, and water resources are under development. In each of these issues, multiple stresses and forces are impacting on the system under study, with global environmental change becoming an increasingly important additional stress. How global change is manifested in various parts of the world affects the resilience or vulnerability of individuals and societies to these stresses. How individuals and societies respond to the challenge of increasing food supplies, improving access to water resources, and managing parts of the carbon cycle will have profound implications for the functioning of the Earth System into the future.

The goals of each of the joint projects are:

Carbon Cycle: to understand the underlying mechanisms and feedbacks that control the carbon cycle, explain the current patterns of sources and sinks, and develop plausible trajectories of carbon cycle dynamics into the future.

Food Systems: to determine strategies to cope with the impacts of global environmental change on food provision and to analyse the environmental and societal consequences of adaptation.

Water Resources: to understand the interactions and feedbacks from local to global scale between human and biophysical systems in an Earth System context, and thereby contribute to the development of sustainable water systems (draft). 


\section{Programme Structure}

Each of the global environmental change programmes is organised around a small number of research projects:

\section{IGBP:}

$B A H C$ : Biospheric Aspects of the Hydrological Cycle

DIS: Data and Information Services (to conclude at the end of 2001) GAIM: Global Analysis, Integration and Modelling GCTE: Global Change and Terrestrial Ecosystems GLOBEC: Global Ocean Ecosystem Dynamics IGAC: International Global Atmospheric Chemistry JGOFS: Joint Global Ocean Flux Study

LOICZ: Land-Ocean Interactions in the Coastal Zone LUCC: Land-Use/Cover Change (co-sponsored by IHDP) PAGES: Past Global Changes SOLAS: Surface Ocean-Lower Atmosphere Study START: Global Change System for Analysis, Research and Training (co-sponsored by IHDP and WCRP)

\section{IHDP:}

GECHS: Global Environmental Change and Human Security IDGEC: Institutional Dimensions of Global Environmental Change IT: Industrial Transformations

LUCC: Land-Use/Cover Change (co-sponsored by IGBP) START: Global Change System for Analysis, Research and Training (co-sponsored by IGBP and WCRP)

\section{WCRP:}

CLIC: Climate and Cryosphere

CLIVAR: Climate Variability and Predictability

GEWEX: Global Energy and Water Cycle Experiment

SPARC: Stratospheric Processes and their Role in Climate

START: Global Change System for Analysis, Research and Training (co-sponsored by IHDP and IGBP)

WOCE: World Ocean Circulation Experiment

\section{DIVERSITAS:}

Core Programme Elements:

- The Effect of Biodiversity on Ecosystem Functioning (with IGBP/GCTE)

- Origins, Maintenance and Change of Biodiversity

- Systematics: Inventorying and Classification of Biodiversity

- Monitoring of Biodiversity

- Conservation, Restoration and Sustainable Use of Biodiversity

Special Target Areas of Research:

- $\quad$ Soil and Sediment Biodiversity (SCOPE)

- Marine Biodiversity

- Microbial Biodiversity

- Inland Water Biodiversity (IUBS)

- Human Dimensions of Biodiversity

- Invasive Species and Their Effect on Biodiversity (GISP)

- Global Mountain Biodiversity Assessment

- International Biodiversity Observation Year
Contacts:

IGBP:

IGBP Secretariat

Royal Swedish Academy of Sciences

Box 50005

S-10405 Stockholm

SWEDEN

Tel: +46-8-16-64-48

Fax: +46-8-16-64-05

Email: sec@igbp.kva.se

Website: http://www.igbp.kva.se/

IHDP:

IHDP Secretariat

Walter-Flex-Str 3

D-53113 Bonn

GERMANY

Tel: +49-228-739-050

Fax: +49-228-739-054

Email:ihdp@uni-bonn.de

Website: http://www.uni-bonn.de/ihdp

WCRP:

WCRP Secretariat

World Meteorological Organisation

CP 2300, 41 avenue Giuseppe Motta

CH-1211 Geneva 2

SWITZERLAND

Tel: +41-22-730-8246

Fax: +41-22-730-8036

Email:dwcrp@gateway.wmo.ch

Website: http://www.wmo.ch/web/wcrp/wcrp-home.html

\section{DIVERSITAS:}

c/o International Council for Science (ICSU)

51, bd Montmorency

75016 Paris

FRANCE

Tel: +33-1-45 250329

Fax: +33-1-42 889431

e-mail: anne@icsu.org

http://www.icsu.org/diversitas/ 
Editors: Will Steffen and PeterTyson

Writing Team: Jill Jäger, Pamela Matson, Berrien Moore III, Frank Oldfield, Katherine Richardson, John Schellnhuber,Will Steffen, Bill Turner II, Peter Tyson, Robert Wasson

Series Editor: Susannah Eliott (IGBP Secretariat)

Layout: IdéoLuck AB, Stockholm

Cover: Cover design and technical support by John Bellamy

Other Contributions: This summary is ultimately the work of thousands of scientists associated with the Global Environmental Change programmes. It is truly a community product. The writing team thanks the following people for particular contributions and careful review: Keith Alverson, Manuel Barange, Guy Brasseur, Wendy Broadgate, Pep Canadell, David Carson, Martin Claussen, Chris Crossland, Paul Crutzen, Helmut Geist, John Ingram, Kathy Hibbard, Holger Hoff, Pavel Kabat, Eric Lambin, Louis Lebel, Peter Liss, Sabine Lütkemeier, João Morais, Daniel Murdiyarso, Tom Pedersen, Alex Pszenny, Henning Rodhe, Suzanne Serneels, Steven Shafer, Gerard Szejwach, Tom Tomich, Meine van Noordwijk, Pier Vellinga, Hassan Virji and the Scientific Committee of the IGBP.

Financial Support: The IGBP syntheis project is supported by the Swedish Millennium Committee and by MISTRA (Swedish Foundation for Strategic Environmental Research), with in-kind support from the Royal Swedish Academy of Sciences. IGBP central funding comes on a voluntary basis from about 50 countries around the world. IGBP and its partner global environmental change programmes work closely with the International Group of Funding Agencies (IGFA) on common issues concerning funding of global change research.

Image Credits: Alternatives to Slash and Burn Programme (Tom Tomich); CLIVAR Project Office; Chris Crossland; European Space Agency (ESA); GCTE (Global Change and Terrestrial Ecosystems) International Project Office; Pavel Kabat; Large Scale Biosphere-Atmosphere Experiment in Amazonia (LBA); National Aeronautics and Space Administration (NASA), USA; Dirk Parsons; Diane Pataki; Remote Sensing and Regional Analysis Laboratory, UCLouvain, Belgium; Katherine Richardson; Suzanne Serneels; Carrie Steffen; Will Steffen; Brian Stocks; US Department of Agriculture Photo Library; H. Weiss; World Data Center for Paleoclimatology slide set (Jerry Wellington)

IGBP Science Series: ISSN 1650-7770

Copyright C IGBP 2001 


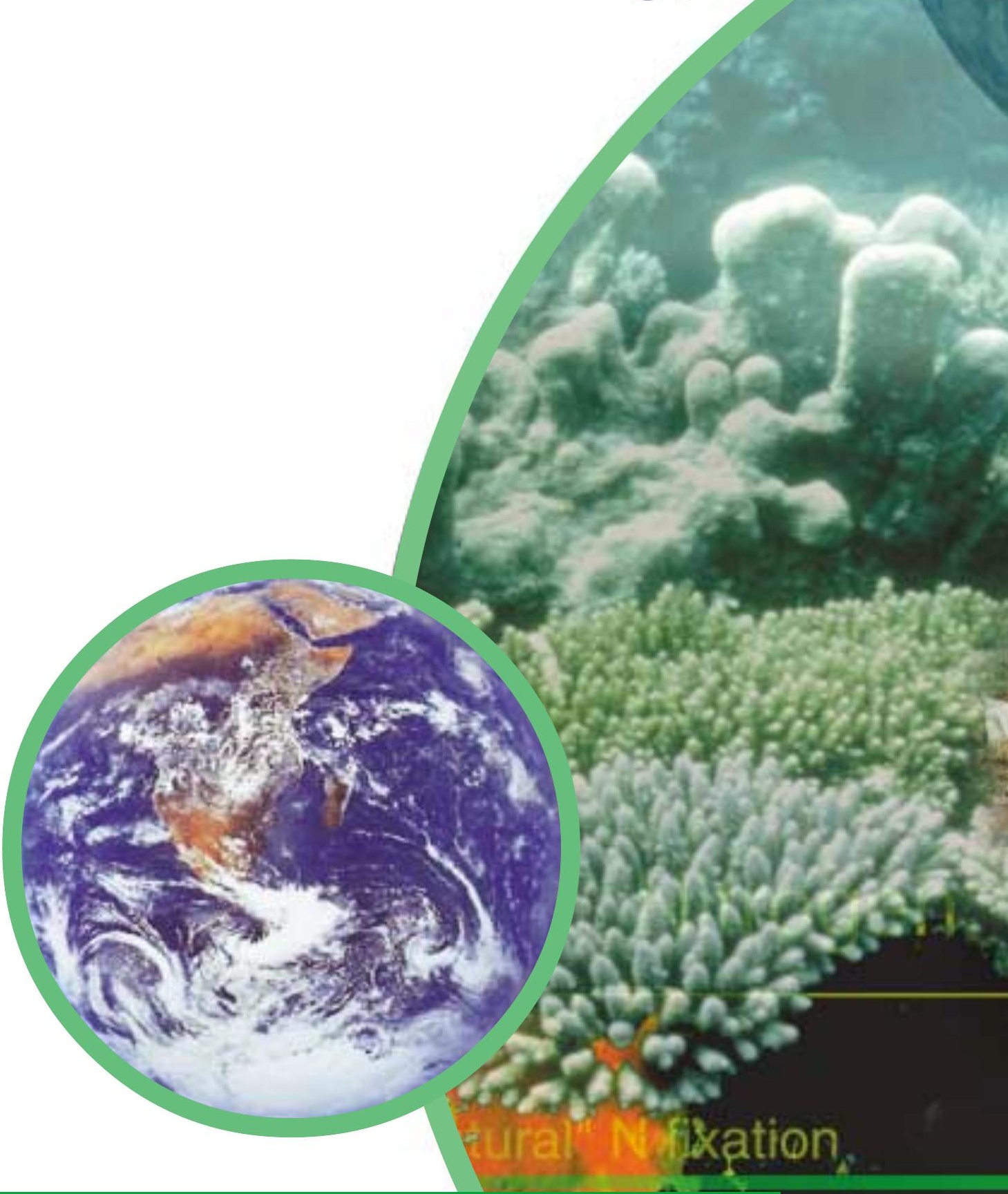

The past decade of global change research, summarised in this booklet, has unveiled more and more about the complex and interrelated nature of the Earth System, and about the ways in which human activities are impacting the System. Much exciting science has been carried out and much has been achieved. Above all, we know that the Earth System has moved well outside the range of natural variability exhibited over the last half million years at least. The nature of changes now occurring simultaneously in the global environment, their magnitudes and rates, are unprecedented in human history, and probably in the history of the planet. The Earth is now operating in a no-analogue state.

The IGBP Science Series is designed to make IGBP's research output accessible to a wider range of audiences, in particular to the policy and resource management communities. These 'visually rich', easy-to-understand reports present the most recent new scientific understanding in major areas of Earth System Science.

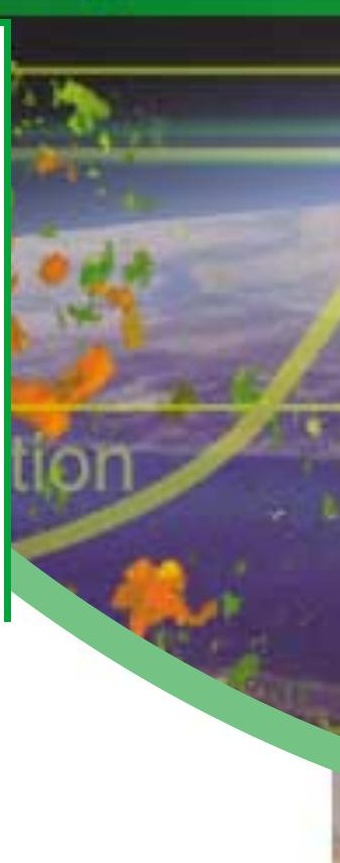

